\title{
pneumonia
}

Review

\section{A review of the role of Haemophilus influenzae in community-acquired pneumonia}

\author{
Mary P E Slack ${ }^{a, b}$
}

${ }^{a}$ Griffith University, Gold Coast Campus, Queensland, Australia; '`nstitute of Hygiene and Microbiology, University of Würzburg, Würzburg, Germany

Corresponding author: Professor Mary P E Slack, Griffith University, Gold Coast Campus, Queensland, Australia. Tel: +61 756780866 email: mpeslack@gmail.com

Author contributions: MPES met ICMJE authorship criteria. MPES contributed entirely to the drafting and writing of the paper. MPES critically reviewed the manuscript for important intellectual content. MPES agrees with the manuscript's results and conclusions.

Received 1 October 2014; Accepted 4 March 2015; Published 29 June 2015

Citation: Slack MP. A review of the role of Haemophilus influenzae in community-acquired pneumonia. pneumonia 2015;6:26-43

\begin{abstract}
In an era when Haemophilus influenzae type b (Hib) conjugate vaccine is widely used, the incidence of Hib as a cause of community-acquired pneumonia (CAP) has dramatically declined. Non-typeable $H$. influenzae (NTHi) strains and, occasionally, other encapsulated serotypes of $H$. influenzae are now the cause of the majority of invasive $H$. influenzae infections, including bacteraemic CAP. NTHi have long been recognised as an important cause of lower respiratory tract infection, including pneumonia, in adults, especially those with underlying diseases. The role of NTHi as a cause of non-bacteraemic CAP in children is less clear. In this review the evidence for the role of NTHi and capsulated strains of $H$. influenzae will be examined.
\end{abstract}

Keywords: pneumonia, $H$. influenzae, NTHi, aetiology, infection 


\section{Introduction}

Community-acquired pneumonia (CAP) is a major cause of morbidity and mortality in children and adults. Those at the greatest risk are young children in developing countries [1], the elderly, and those with chronic respiratory disease. The implementation of pneumococcal and Haemophilus influenzae type b ( $\mathrm{Hib})$ conjugate vaccination in many countries has resulted in a reduction in the global number of CAP episodes in young children over the past decade, but pneumonia remains a leading cause of morbidity and mortality in this age group [2]. Walker et al [3] estimated that in 2010 there were 120 million episodes of pneumonia worldwide, 14 million of which progressed to severe pneumonia requiring hospitalisation [4], and 1.3 million deaths in children aged less than 5 years [3], of which $81 \%$ occurred in the first two years of life [3]. Pneumonia, particularly severe and recurrent pneumonia, in young children is a risk factor for chronic suppurative lung disease and bronchiectasis in childhood [5-7], which are both debilitating and risk factors for premature death [8]. Streptococcus pneumoniae is the most commonly identified bacterial pathogen in CAP in both children and adults, followed by Mycoplasma pneumoniae, $H$. influenzae, Chlamydophila pneumoniae and Legionella pneumophila [9]. Both capsulated and non-capsulated or non-typeable strains of $H$. influenzae (NTHi) can cause pneumonia. Hib was one of the most common causes of invasive $H$. influenzae infection, including bacteraemic pneumonia in young children, whereas NTHi was generally considered to be a major cause of chronic respiratory infections and pneumonia in adults. However, following the introduction of $\mathrm{Hib}$ conjugate vaccines, the incidence of invasive Hib disease, including pneumonia, has declined dramatically in all countries where they are routinely used [10]. In this paper the current role of $H$. influenzae as a causative agent of pneumonia in children and adults will be reviewed. Relevant studies were identified by searching PubMed and Google Scholar for articles (published in English) including in their titles or abstracts the term "Haemophilus influenzae" combined with the any of the following terms: "pneumonia", "community-acquired pneumonia", "respiratory tract infection", "epidemiology", "burden", "incidence", "carriage", "aetiology", "mortality", "morbidity", "children", "adults", "vaccination", "co-infection", "respiratory viruses", "interaction", "microbiology", "laboratory diagnostics", or "taxonomy". More citations were identified from references in these initial searches.

\section{Microbiology}

Haemophilus spp are pleiomorphic Gram-negative coccobacilli. $H$. influenzae is the major human pathogen in the group. Some strains of $H$. influenzae are encapsulated whilst others are non-encapsulated. There are six distinct antigenic serotypes of encapsulated $H$. influenzae designated a-f on the basis of their capsular polysaccharide. Hib has a polyribosyl ribitol phosphate capsule. NTHi strains cannot be serotyped by conventional type-specific antiserum agglutination. The different serotypes and NTHi vary in their pathogenic potential. Margaret Pittman [11] noted that most invasive disease was caused by Hib strains. whereas the majority of respiratory tract isolates were NTHi. The other capsulated serotypes are less common causes of infection.

The differential requirements for two accessory growth factors, X-factor (haemin) and/or V-factor (nicotinamide adenine dinucleotide), are important criteria for defining the Haemophilus spp. $H$. influenzae requires both $\mathrm{X}$-factor and V-factor. Besides $H$. influenzae, a second X-and V-factor dependent species, $H$. haemolyticus, is frequently found in the upper respiratory tract and has long been regarded as a commensal. Until recently, microbiologists relied on the production of zones of $\beta$-haemolysis on horse blood agar to differentiate $\mathrm{H}$. haemolyticus from NTHi. However, $10-40 \%$ of strains of $H$. haemolyticus are non-haemolytic [12] and several molecular methods have been proposed to accurately identify $H$. haemolyticus $[13,14]$.

The capsular serotype of $H$. influenzae is traditionally determined by slide agglutination using type-specific antisera. This method is prone to misinterpretation, with problems of auto-agglutination, cross-reacting antisera, and observer variation. The definitive method of typing $H$. influenzae is capsular genotyping using a polymerase chain reaction (PCR)-based method [15]. Molecular typing will allow accurate differentiation between typeable and non-typeable strains. It will also, if the appropriate primers are used, distinguish true NTHi strains from $H$. haemolyticus and also from strains of $H$. influenzae that contain a complete or partial capsule locus. Strains with a partial capsule locus (capsule-deficient mutants, Hib-minus or Hib- strains) are unable to export polysaccharide to the cell surface and thus will appear to be NTHi because they are non-typeable by conventional means. NTHi and $H$. haemolyticus may also be differentiated by matrix-assisted laser desorption/ ionisation time-of-flight mass spectrometry (MALDI-TOF) [14], which is increasingly becoming available in diagnostic clinical laboratories.

\section{H. influenzae carriage}

$H$. influenzae is only found in humans and colonises the nasopharynx and throat, and to a lesser extent the conjunctivae and genital tract. The respiratory tract is mainly colonised by $H$. parainfluenzae and NTHi. In developed countries, approximately $20 \%$ of infants will be colonised with NTHi in the first year of life and the rate increases over time with more than $50 \%$ of children aged 5 years carrying NTHi [16]. Carriage rates are much higher in children in developing countries and in indigenous communities, where NTHi carriage is established very soon after birth $[17,18]$. Carriage is a dynamic process and different patterns of colonisation are seen in the first two years of life, ranging from short-term colonisation with a single strain, to prolonged colonisation with one strain, to recurrent colonisation with different or 
multiple strains [18-20]. Children in day-care centres have both higher rates of colonisation with NTHi and more frequent transmission of strains compared to controls [21]. NTHi also colonise the upper respiratory tract of $20-30 \%$ of healthy adults $[22,23]$. NTHi are found in $30-40 \%$ of sputum cultures from patients with stable chronic obstructive pulmonary disease (COPD) $[24,25]$ and approximately $50 \%$ during acute exacerbations of COPD [24-27]. These figures, based on traditional bacteriological culture, may be underestimates as studies using PCR have confirmed higher detection rates of NTHi in COPD [28]. The published data on the prevalence of lower respiratory tract colonisation with NTHI in healthy adults is based on small numbers of subjects but indicates that NTHi was present in $0-4 \%$ of subjects $[25,27]$. Children frequently carry multiple strains of NTHi [29].

Transmission occurs through the spread of respiratory droplets or contact with respiratory secretions. Adults with COPD may carry multiple strains of NTHi [30] and the acquisition of a new strain may be associated with an acute exacerbation [31]. There is also evidence that the combination of NTHi and rhinovirus infection can increase the severity of acute exacerbations [32]. Immunity to one strain of NTHi does not confer protection against colonisation by a different NTHi strain, nor does it prevent infection [33].

The carriage rate of capsulated strains of $H$. influenzae is much lower. In unvaccinated populations, $3-5 \%$ of infants and $8-12 \%$ of pre-school age children are colonised by $\mathrm{Hib}$, with higher rates being found in children attending day-care centres [21], and among household members of a case of invasive Hib disease [34]. By the age of 5 years, almost all children in unvaccinated populations would have been colonised at some time by Hib.

\subsection{Interaction between $H$. influenzae and respiratory viruses}

In 1889-1992 an epidemic of influenza occurred in Western Europe. Richard Pfeiffer [35,36] examined sputum from patients suffering from influenza and described seeing almost pure cultures of a Gram-negative bacillus in the majority of samples. He postulated that Bacillus influenzae (Pfeiffer's bacillus or $H$. influenzae) was the cause of influenza. In 1922, Kristensen [37] proposed that this organism was a secondary invader rather than the primary cause of influenza. In 1933, Smith, Andrewes, and Laidlaw [38] established that a virus caused influenza. A major cause of death in epidemics of viral influenza is superinfection with a bacterial pathogen, most commonly S. pneumoniae, but other common respiratory pathogens, including $H$. influenzae, Staphylococcus aureus and Group A streptococci have predominated in different pandemics or geographical locations [39].

Exacerbations of COPD are often associated with viral and bacterial co-infection. The most common finding is coinfection with rhinovirus and $H$. influenzae, which is also associated with increased severity of the exacerbations $[26,40]$.

The interaction between respiratory viruses and bacterial pathogens is multifactorial and complex [41,42]. Respiratory viral infections render the epithelial surface more susceptible to bacterial colonisation [43] by disrupting the epithelial barrier [44] whereby rhinovirus infection can facilitate paracellular migration of NTHi [45]. Furthermore, viruses impair mucociliary velocity and reduce bacterial clearance [44]. Viral infection also triggers a pro-inflammatory response, upregulating adhesion proteins in respiratory epithelial cells. For example, rhinovirus upregulates intracellular adhesion molecule 1 (ICAM-1), which facilitates not only its own invasion but also NTHi adhesion [46,47]. Respiratory viruses impair neutrophil function by decreasing the oxidative burst and enhancing neutrophil apoptosis, which increases susceptibility to bacterial superinfection [48]. In addition, viruses induce production of interferons (IFNs), IFN- $\alpha$ and IFN- $\beta$, which also impair neutrophil responses [49] and IFN- $\gamma$ down-regulates macrophage activity thus impairing bacterial clearance [50]. Respiratory viruses also interact with Toll-like receptors (TLRs) desensitising the lung sentinel cells to bacterial ligands [51]. The interaction is not entirely one way since NTHi stimulates the expression of ICAM-1 and TLR-3 on human epithelial cells, facilitating rhinovirus entry [45].

\section{Spectrum of infections caused by $H$. influenzae}

$H$. influenzae is associated with two types of infection, invasive and non-invasive infections, which have distinctive epidemiologic profiles.

\subsection{Invasive infections}

Prior to the introduction of Hib conjugated vaccines, Hib was one of the most common causes of meningitis and pneumonia in infants and young children under the age of 5 years. In England and Wales, $90 \%$ of invasive $H$. influenzae infections were caused by $\mathrm{Hib}, 10 \%$ by NTHi, and less than $1 \%$ by other serotypes; $23 \%$ of NTHi infections occurred in children less than 5 years of age [52]. Bacteraemia with no obvious focus of infection was the commonest presentation of invasive NTHi infection (37\%) followed by bacteraemic pneumonia (27\%) and meningitis (12\%).

The addition of Hib conjugate vaccines to infant immunisation programmes has resulted in a dramatic decline in invasive Hib infections in every country where they have been used, through a combination of direct and indirect (herd) protection [53,54]. Polysaccharideprotein conjugate vaccines have the capacity to reduce nasopharyngeal carriage of the target organism of the vaccine serotype/serogroup, which provides the basis of herd protection. Hib vaccination has no effect on the carriage of other serotypes of $H$. influenzae or NTHi, which can also, albeit less frequently, cause invasive infections including bacteraemic pneumonia [55]. 


\subsection{Non-invasive infections}

$H$. influenzae can cause a range of non-invasive infections of mucosal surfaces. NTHi is the predominant bacterial pathogen in respiratory tract infections in both children and adults: otitis media in infants and young children, sinusitis in older children and adults, non-bacteraemic pneumonia in elderly adults, and acute exacerbations of COPD in adults [55].

\section{Determining the aetiology of community-acquired pneumonia (CAP)}

There are a number of challenges facing any review of the aetiology of CAP. Pneumonia can be defined as an inflammatory response to infection in the alveoli and distal airways. Although this can be confirmed histologically, the clinical and radiological presentations are extremely diverse. The Pneumococcal Vaccines Accelerated Development and Introduction Plan (Pneumo-ADIP) developed a case definition for childhood pneumonia, based on cough, respiratory difficulty, and tachypnoea [56]; however, many published studies use different case definitions, making comparisons difficult.

Since NTHi are such common members of the upper respiratory tract flora, and mucosal infections are frequently polymicrobial, differentiating colonising commensals from the causative pathogen(s) is challenging. In the case of lower respiratory tract infections, including pneumonia, these uncertainties are compounded by difficulties in obtaining specimens that accurately reflect the microbiology of the lower respiratory tract. Sputum cultures are generally contaminated with upper respiratory tract flora and results should be carefully evaluated by considering the quality of the specimen. A commonly used approach is the molecular analysis of the cellular composition of sputum [57] where any sputum that contains $>25$ squamous epithelial cells/low power field in a 100x magnification of a Gram-stained smear of the sample is discarded. Another approach is quantitative cultures of expectorated sputum, where the expected threshold for significance of any potential pathogen is $\geq 10^{6}$ colony forming units (cfu)/ml [58].

Young children cannot produce adequate sputum samples unless sputum is induced with inhalations of hypertonic saline and nasopharyngeal aspiration. Although sputum induction appears to produce good quality samples for microbiological analysis, the procedure is not recommended for routine use as children generally find it unpleasant [59].

Broncho-alveolar lavage (BAL) is a more reliable sample as it is less likely to be contaminated by organisms in the upper airway. Quantitative culture of BAL specimens or samples collected through double-lumen brush catheters, using a threshold of $\geq 10^{4} \mathrm{cfu} / \mathrm{ml}$, can improve the determination of the aetiology of non-bacteraemic CAP $[60,61]$. A transthoracic needle aspiration or diagnostic lung tap will assist in determining the aetiology in both children and adults [62-66], but in practice this procedure is impractical in the majority of cases of CAP, despite being a generally safe procedure with a low complication rate [65].

Serological tests may be used to detect a range of viruses and atypical pathogens but are often of limited use in clinical practice due to the requirement for acute and convalescent sera. S. pneumoniae and L. pneumophila antigen may be detected in urine and provide a diagnosis of CAP, though for the pneumococcus this test is unreliable in young children as a positive result may simply reflect the high load of pneumococci carried in the nasopharynx. No such test is currently available for $H$. influenzae, and would suffer from the same drawbacks as pneumococcal urinary antigen detection.

Quantitative real-time PCR (qRT-PCR) to detect $S$. pneumoniae and $H$. influenzae genes in serum or whole blood is a possible approach to the diagnosis of CAP. Rello et al [67] used qRT-PCR to detect pneumococcal DNA (lytA) in the blood of $62 \%$ of adults with confirmed or probable pneumococcal CAP. Blood cultures were positive in only $37 \%$ of the patients. This study also reported a correlation between bacterial DNA load and the risk of septic shock or death. Patients who had been pre-treated with antibiotics were excluded. Other groups included such patients in their studies with similar findings $[68,69]$. These studies were in adults. In paediatric CAP there is a concern that high rates of nasopharyngeal carriage may result in false positive results. Lai et al [70] demonstrated that dense upper respiratory tract colonisation with $S$. pneumoniae and $H$. influenzae did not produce false positive results when qRT-PCR was performed to detect $S$. pneumoniae lyt $A$ and $H$. influenzae glpQ genes in serum samples from Indigenous Australian children with a bacterial load of up to $10^{6} \mathrm{cfu} / \mathrm{ml}$ in matched nasopharyngeal swabs. This was a pilot study using spiked sera. Its applicability in clinical samples from children with suspected CAP is awaited. There is a need for standardisation of methodologies, "cutoff" values, and gene targets if meaningful comparisons are to be made between published studies $[71,72]$.

The use of new methods for identifying the cause of CAP has produced evidence that many cases of CAP may be the result of mixed infections with either viral and bacterial or mixed bacterial aetiology in both adults and children [7376]. The presumption in the case of mixed viral-bacterial aetiology is that a preceding upper respiratory tract viral infection predisposes the patient to a supervening bacterial infection.

An assay for specific biomarkers, such as procalcitonin, in conjunction with qRT-PCR has been proposed to differentiate viral from bacterial pneumonia [77]. However, since up to $30 \%$ of children hospitalised with CAP have coinfection with viruses and bacteria [73], this may be of limited use as a diagnostic test. 
Slupsky et al $[78,79]$ reported that nuclear magnetic resonance metabolomics may offer a way of differentiating pneumococcal pneumonia from other viral and bacterial causes of pneumonia, and may be a way of identifying children with severe pneumonia [80]. Since specific microbes produce unique urinary metabolites in the urine [81], this approach may be sufficiently specific to identify $H$. influenzae CAP. Whether this approach can be used to distinguish NTHi from other types of $H$. influenzae as a cause of pneumonia is unclear.

Several authoritative guidelines on the management and treatment of CAP state that it is not necessary to perform any microbiological investigations on cases of mild CAP in adults and children that do not require hospitalisation [8285]. The rationale for this advice is that the investigations will not alter the management of the patient in the majority of cases. If the patient fails to respond to empirical antimicrobial therapy or requires hospitalisation, then the guidelines do recommend investigations. If the patient has already received broad-spectrum antimicrobial therapy, the likelihood of obtaining accurate information on the microbiological aetiology of the CAP is markedly reduced. The result of this is that the microbiological aetiology of non-bacteraemic CAP is ill-defined. The consequences of such an approach are not only that the causative pathogen(s) are not identified in the individual patient, but also that it hampers any assessment of the impact of vaccinations and may result in unnecessary antimicrobial therapy.

Radiological signs of alveolar consolidation are considered the most specific indicator of bacterial pneumonia $[86,87]$. To assess the reliability of paediatric chest radiograph interpretation, three paediatric sub-specialists (infectious diseases, radiology and respiratory medicine) reviewed 3,033 chest radiographs taken from children aged $<5$ years presenting with an acute febrile illness. The radiologist was most likely (21.3\%) and respiratory physician least likely $(13.7 \%)$ to diagnose consolidation. The overall percentage agreement for pairs of readers was $85-90 \%$. However, chance corrected agreement between the readers was moderate, with kappa scores of $0.4-0.6$. The estimated sensitivity ranged from 0.71 to 0.81 across readers, and specificity 0.91 to 0.98 [88]. However, as with microbiological investigations for pneumonia, many cases of CAP will be treated in the community and will not receive a chest radiograph.

If bacteraemic pneumonia is suspected, blood cultures should be taken. However, the sensitivity of blood cultures is generally low, especially when antimicrobial chemotherapy has already been initiated and the yield of significant pathogens from blood cultures ranges from $13-$ $27 \%$ in children with complicated CAP, but is less than $5 \%$ in those with mild or moderate CAP $[89,90]$. $H$. influenzae is a highly fastidious organism and the recovery of this bacterium is highly dependent on both the blood culture broth and the media that are used for subculturing any potentially positive blood cultures [91]. Delay in incubating the blood cultures and the presence of antimicrobials in the blood will considerably reduce the chance of recovering $H$. influenzae. Commercial blood culture systems provide quality assured blood culture broths that do support the growth of $\mathrm{H}$. influenzae, but it is also important to use appropriate media that contain adequate concentrations of $\mathrm{X}$ - and $\mathrm{V}$-factors when subculturing any bottles that signal "positive". Blood cultures may therefore significantly underestimate the presence of pathogens, including $H$. influenzae, in the lower respiratory tract. An alternative approach to conventional blood cultures is the detection of bacterial DNA by RT-PCR from dried blood spot samples placed on specialised filter papers, such as FTA $^{\circledR}$ Elute (GE Healthcare Life Sciences, USA) [92].

\section{6. $\quad H$. influenzae as a cause of community-acquired pneumonia (CAP)}

Hib, other capsulated serotypes, and NTHi can all cause pneumonia, which may be bacteraemic or nonbacteraemic in both children and adults.

\subsection{Hib}

Hib was a major cause of bacterial pneumonia in children prior to the introduction of Hib conjugate vaccines. Evidence for this is provided from surveys of bacteraemic infections in children, lung aspiration studies, and vaccine probe studies [93]. Vaccine probe studies from The Gambia indicated approximately $20 \%$ of severe pneumonia cases in young children were caused by Hib [94]. The widespread use of Hib conjugate vaccines has resulted in a decline in the number of cases of Hib disease, including bacteraemic pneumonia, wherever the vaccine has been implemented. However, invasive Hib infections do still occur. For example, prospective, enhanced population-based surveillance of invasive $H$. influenzae disease has been undertaken in England and Wales since 1990 [95]. Prior to the introduction of the Hib conjugate vaccine, invasive $H$. influenzae disease was predominantly caused by $\mathrm{Hib}(90 \%)$ with $90 \%$ of cases occurring in young children. Meningitis was the most common presentation (56\%) of Hib infection, with bacteraemic pneumonia accounting for $5 \%$ of cases overall ranging from $3 \%$ of the cases in children $<15$ years of age to $31 \%$ in adults. NTHI was responsible for $10 \%$ of invasive $H$. influenzae disease, and bacteraemic pneumonia was the clinical presentation in $13 \%$ of children $<15$ years of age and $34 \%$ of adults [52].

The Hib conjugate vaccine was incorporated into the UK infant immunisation schedule in 1992. Since that time, the incidence of invasive Hib disease in children $<5$ years of age has fallen from 35.5 per 100,000 in 1990 to 0.06 per 100,000 in 2012 [96]. Concomitant with the changing incidence, the age distribution of invasive Hib disease and its clinical presentation has altered. Of 106 cases of invasive Hib disease occurring over a 4-year period (2009-2012), $73 \%$ occurred in adults (Figure 1), often with pre-existing co-morbidities, and $56 \%$ of the adult cases presented as a bacteraemic pneumonia [96]. 


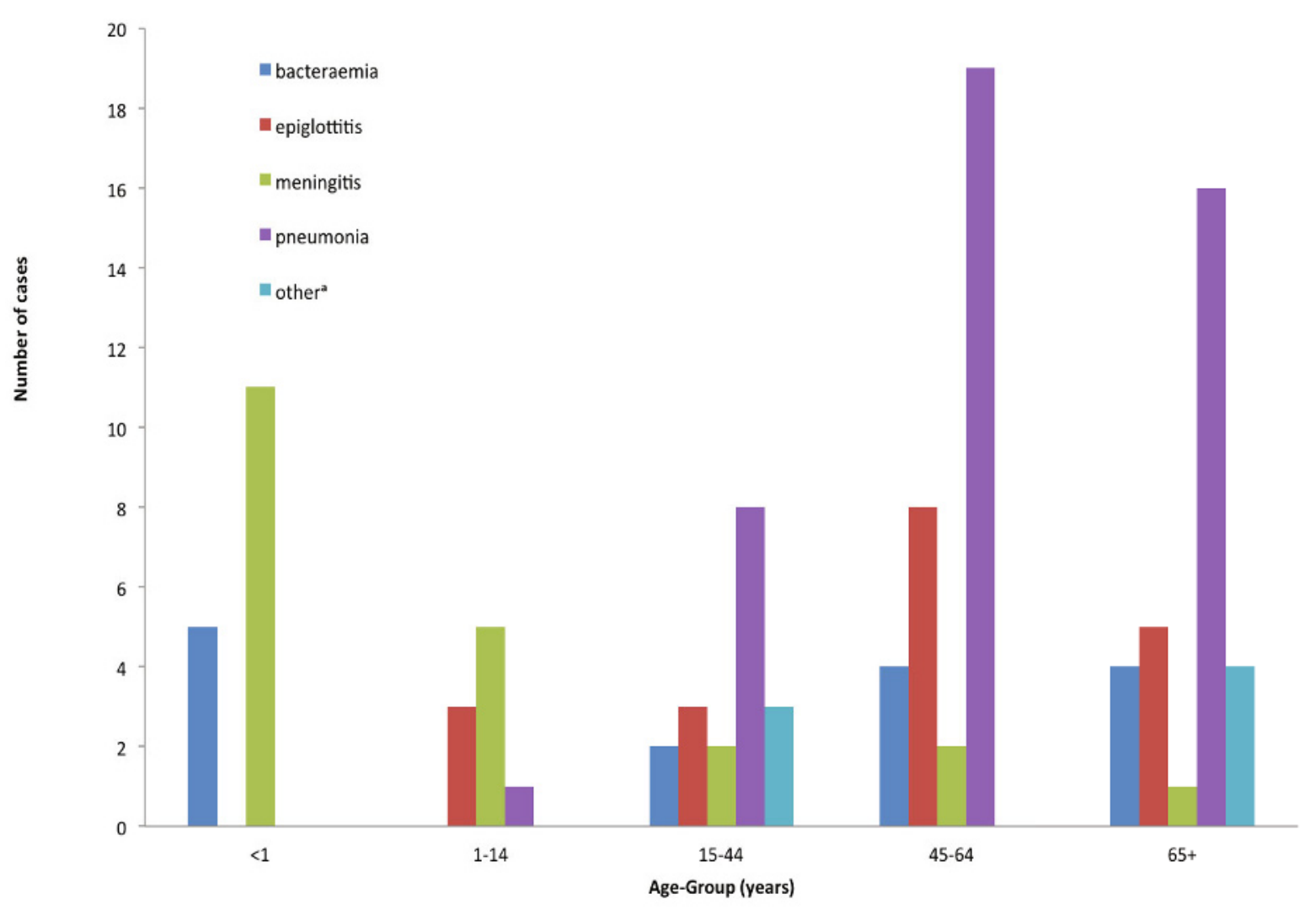

Figure 1 Cases of invasive Haemophilus influenzae type b (Hib) disease in England and Wales, 2009-2012, by age and clinical presentation (Based on data from the Public Health England surveillance of invasive H. influenzae infections. Available from https:// www.gov.uk/government/collections/Haemophilus-influenzae-guidance-data-and-analysis)

${ }^{a}$ cholecystitis, discitis, endocarditis, and genitourinary infections

Invasive Hib disease is principally found in adults, often with pre-existing medical conditions who often present with pneumonia [96]. Hib remains a leading cause of pneumonia in children in countries that have not yet introduced the Hib conjugate vaccine [97].

\subsection{NTHi and Non-type b capsulated H. influenzae}

A major concern following the introduction of routine immunisation against Hib was that as conjugate vaccines also prevent carriage, other $H$. influenzae serotypes or NTHi might fill the ecological niche in the nasopharynx and, consequently, lead to increased risk of invasive disease [98]. These concerns have so far remained unfounded, with no conclusive evidence for replacement disease. However, because of the success of the Hib conjugate vaccine, NTHI has become by far the most common cause of invasive and non-invasive $H$. influenzae infections across all age groups in countries with established Hib vaccination programmes [98].

\subsubsection{NTHi}

NTHi are a recognised cause of both bacteraemic and non-bacteraemic pneumonia in both children and adults, though the data on the relative importance of NTHi in the microbial aetiology of paediatric pneumonia are limited and to some extent conflicting [99]. Silverman et al [62] investigated 88 Nigerian children (aged 4 months to 8 years) with severe, untreated, acute pneumonia. Using standard bacteriological culture of blood and nasopharyngeal secretions plus needle aspiration of consolidated lung tissue, they identified $H$. influenzae in $10 / 88(14.3 \%)$ lung aspirates. The isolates were all negative when tested by counter-current immunolectrophoresis with $\mathrm{Hib}$ antiserum. This confirmed that the isolates were not $\mathrm{Hib}$ and it is reasonable to assume that some, if not all, of the isolates were NTHi. Studies from Papua New Guinea, The Gambia, and Pakistan in the 1980s suggested that, in these communities, NTHi was a major cause of pneumonia in children [100-104]. Using blood cultures and lung aspiration, Shann and colleagues [100] studied the aetiology of pneumonia in 83 children admitted to hospital in Goroka, Papua New Guinea. H. influenzae was the predominant pathogen, being found in 33/83 (40\%) of the cases. Pneumococci were identified in $34 \%$ and M. catarrhalis in $11 \%$ of the cases [100]. Of the haemophili typed, Hib accounted for 19\% (6/32) of infections and $56 \%(18 / 32)$ were NTHi. Co-detection of $H$. influenzae and S. pneumoniae occurred in $22 \%$ of the children. Wall et al [102] reported a study of lung aspirates and blood collected from 64 Gambian patients with pneumonia, including 51 children aged $<10$ years. They found S. pneumoniae in $51 \%(26 / 51)$ of children aged $<10$ years of age and $H$. influenzae in $23 \%(11 / 49)$ of the children aged $<5$ years. Of the haemophilus isolates, 31\% (4/13) were 
NTHi. A study of acute lower respiratory tract infections in children from Pakistan $[103,104]$ identified $H$. influenzae and S. pneumoniae in $10 \%$, respectively, of 1,331 cases of pneumonia, and NTHi accounted for $32 \%$ (34/105) of the haemophilus isolates isolated from blood cultures.

A more recent study of 55 children (aged 2-59 months) with pneumonia from The Gambia [105] reported improved detection rates when using PCR as opposed to culture for both S. pneumoniae (25\% [14/56] versus $91 \%$ [48/53]) and $H$. influenzae (5\% [3/56] versus $23 \%$ [12/53]). Yin et al [106] prospectively studied 1,158 children admitted to hospital over three 1-year periods in Singapore with community-acquired LRTI. Non-type b $\mathrm{H}$. influenzae (presumably NTHi) was identified as the causative agent in $9 \%(101 / 1,158)$ of cases. NTHi was found in 50/479 (10.4\%) children aged $<1$ year, in $47 / 532$ (8.8\%) children aged $1-5$ years, and in $4 / 147$ (2.7\%) children aged $>5$ years. Rahman et al [107] examined blood cultures collected from 1,493 children aged $<5$ years admitted with pneumonia to three hospitals in Dhaka, Bangladesh over the period 19992003. They identified 25 cases of bacteraemic CAP caused by $H$. influenzae: $15 \mathrm{Hib}, 6 \mathrm{NTHi}, 3$ serotype c (Hic), and 1 serotype $\mathrm{d}(\mathrm{Hid})$. The majority of these infections occurred in infants aged between 4 and 12 months.

In a retrospective study of CAP aetiology [61], flexible bronchoscopy with BAL was performed on 127 children with acute non-responsive CAP and 123 children with recurrent CAP. The children ranged in age from 1 month to 15 years (median age 33 months) and were otherwise healthy. Children with severe or chronic disease (cystic fibrosis, asplenia, bronchopulomonary dysplasia, primary ciliary disease, immunodeficiency, and tuberculosis) were excluded from the analysis. An infectious agent was identified in $76.0 \%(190 / 250)$ of cases, and aerobic bacteria were isolated in $51.2 \%(128 / 250)$ of the infections: namely $H$. influenzae, $M$. catarrhalis and $S$. pneumoniae in $75.0 \%$ (96/128), $28.9 \%(37 / 128)$ and $13.3 \%(17 / 128)$ of cases, respectively. Almost all of the $H$. influenzae isolates (97.9\% [94/96]) were NTHi. The identification of NTHi was confirmed by conventional serotyping and PCR and the strains were also distinguished from $\mathrm{H}$. haemolyticus. NTHi were identified in $26.0 \%(33 / 127)$ of cases of nonresponsive CAP and $51.2 \%(63 / 123)$ of cases of recurrent CAP. These studies provide details of the serotyping of the $H$. influenzae isolates (Table 1). Unfortunately, most of the other studies in the literature do not give any data on serotyping and so it is difficult to know what proportion of infections were due to NTHi, Hib, or other capsulated serotypes. A systematic review and meta-analysis of CAP in children in Latin America and the Caribbean [108] found that $H$. influenzae ranked first as a cause of CAP in infants aged 0-23 months. The authors noted that all of the included studies took place before 2000, at a time when most Latin American countries had not yet introduced the Hib conjugate vaccine, and so they presumed Hib probably caused most of these infections. However, no data on serotyping was given in the paper. A recent review of the global epidemiology and aetiology of childhood pneumonia in 2010 [2], which summarised the causative pathogens in childhood CAP in 192 countries, gave data for $H$. influenzae CAP with no breakdown of the data by serotype. It is to be hoped that future studies, such as the large ongoing project funded by the Gates Foundation (the Pneumonia Etiology Research for Child Health [PERCH] study) [109] will be able, by using molecular and conventional techniques, to determine the relative importance of Hib, NTHi and nontype $b$ capsulated serotypes of $H$. influenzae as causative agents in childhood CAP.

Several studies have examined serological evidence of a pathogenic role for NTHi in lower respiratory tract infections [110-114]. Claesson and colleagues [110,111] measured the serum antibody responses to NTHi in 38 children (mean age 4.4 years) with radiologically proven pneumonia in whom NTHi in the nasopharynx was the only potential causative pathogen, and in 38 age, sexmatched children with radiologically proven pneumonia in whom NTHi was not isolated. Sixteen out of $38(42 \%)$ cases of the NTHi group had significant antibody responses (IgG, $\operatorname{lgM}$, or both) to a preparation of NTHi outer membrane proteins, compared to $2 / 38(5.2 \%)$ of the control group ( $p<0.001, \mathrm{z}$ test for comparison of 2 proportions). Korppi et al [112] studied 449 children aged $<15$ years hospitalised for respiratory tract infections. Serological evidence of NTHi infection was demonstrated in $6 \%$ of the children. An infection focus was demonstrated in 25 children with NTHi infection, and in 10 cases this was pneumonia. The authors concluded that NTHi is a genuine respiratory tract pathogen in children, but NTHi infections appear to be secondary to preceding viral or bacterial infections in children. Juven et al [73] carried out a 3-year prospective study of 254 children with CAP. NTHi was identified in 22 cases $(9 \%)$, frequently in association with evidence of a viral infection.

In adults the role of NTHi as a cause of pneumonia is well-recognised [115]. Everett et al [116] reported 18 cases of $H$. influenzae pneumonia in adults aged 17-87 years, of whom the majority were $>50$ years of age. The patients were admitted to an Army Medical Center over a 3-year period (1973-1976) but the paper does not state the total number of cases (i.e. the denominator) of pneumonia studied. Eleven of the patients had comorbidities. Transtracheal aspirates and blood cultures were performed. Unfortunately only 5 of the isolates were serotyped, but 4/5 were NTHi. Gotfried [117] reported on 610 cases of CAP in adults $\geq 18$ years seen in the primary care setting in the USA. Sputum samples, either expectorated or induced were collected and mailed to a central laboratory for processing. Sputum samples with $>25$ neutrophils and $<10$ squamous epithelial cells per low power field were deemed suitable for microbiological culture. Of the 610 samples submitted, 204 yielded positive cultures and $H$. influenzae was the most prevalent (38\%) organism identified. The strains of $H$. influenzae were not typed but it is probable that the majority were NTHi. More than $50 \%$ of the patients were smokers or had a history of COPD. Another study conducted in Papua New Guinea 


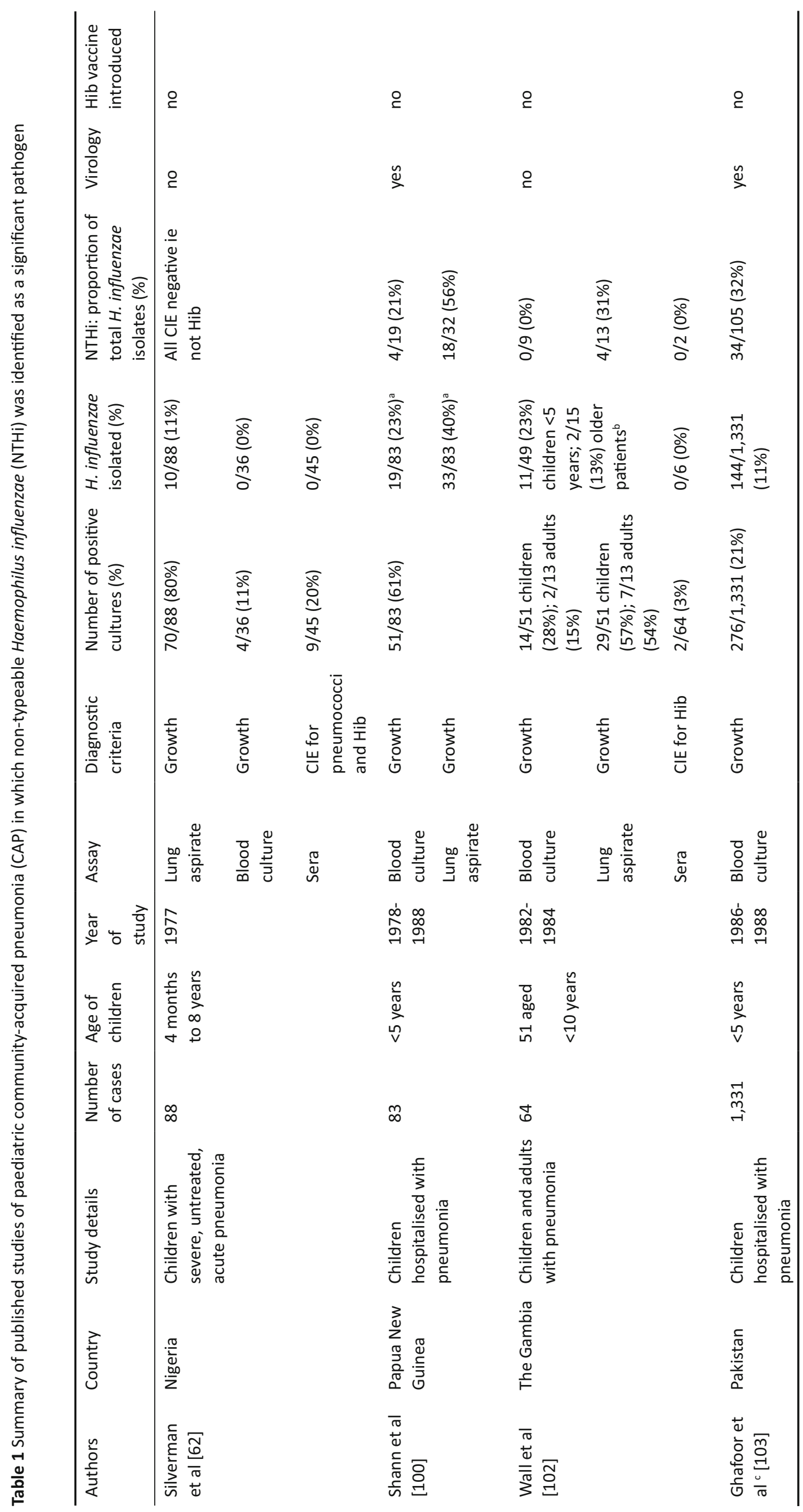




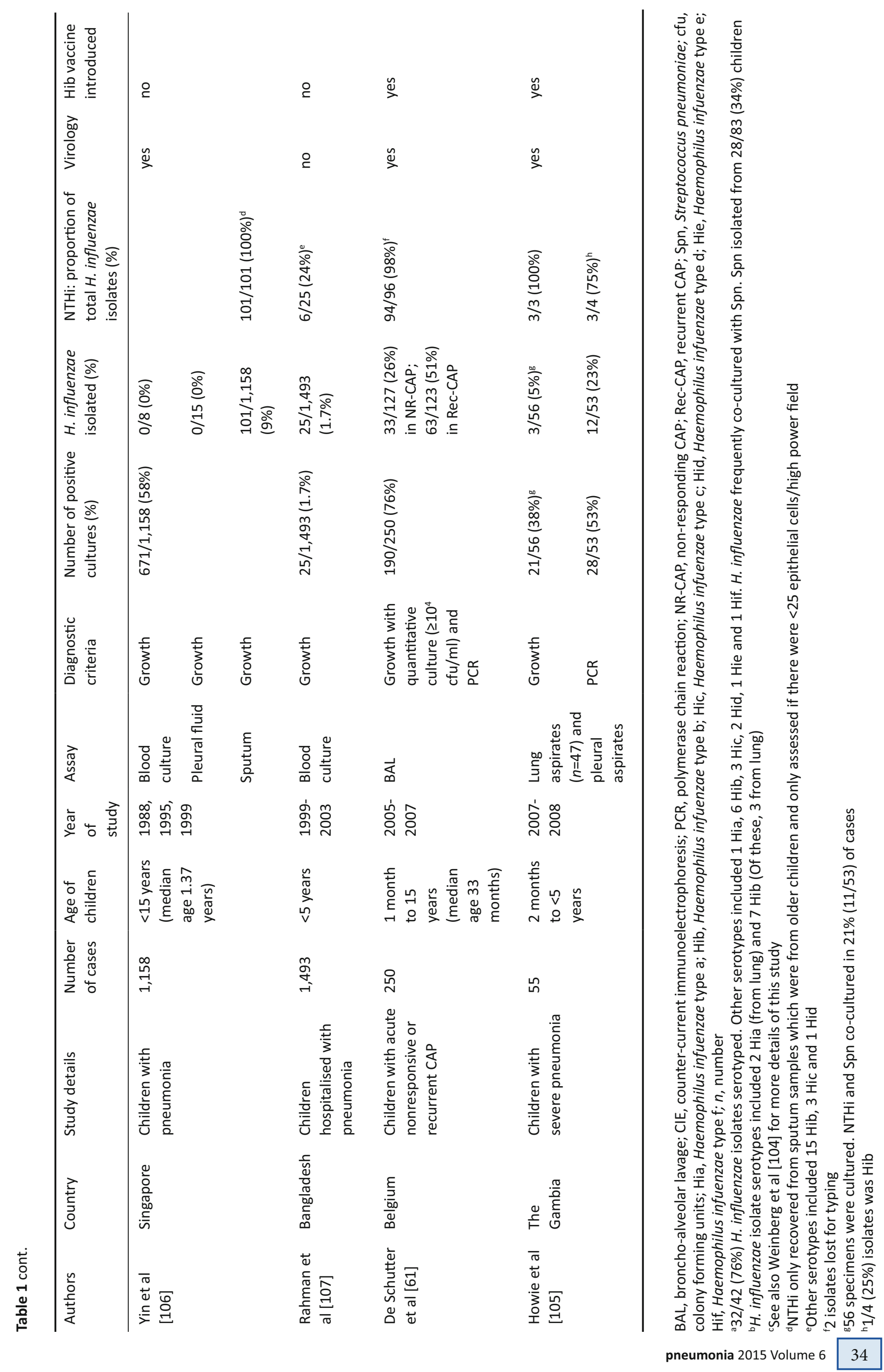


prospectively examined 170 adult patients with acute CAP. Of these, $H$. influenzae was identified as the sole pathogen in 15 (9\%) patients: $7 \mathrm{Hib}, 4$ serotype a (Hia), $1 \mathrm{Hic}$, and 3 NTHi [118]. Chronic lung disease was more common in patients with $H$. influenzae pneumonia than CAP due to other organisms. A further report from these investigators [119] identified Gram-negative bacilli, including H. influenzae, in $26 \%$ of the 90 culture positive percutaneous lung aspirates performed on 144 adult patients with CAP. However, no details on the serotypes of the strains are reported. Janssens and Krause [120] reviewed pneumonia in the elderly and noted that $H$. influenzae is amongst the most frequently reported pathogens in older patients with CAP (up to 14\%) and was identified in 7\% (4/57) of elderly patients with severe CAP requiring admission to an intensive care unit [121]. NTHi is frequently linked to acute exacerbations of COPD and bronchiectasis and should be regarded as a potential pathogen in these patients [122].

Campos et al [123] reported on invasive $H$. influenzae infections in the Madrid, Spain, area over a 2-year period (Jan 1999-Dec 2000) at a time of widespread use of the Hib conjugate vaccine. Of the $H$. influenzae isolates, $67 / 91$ $(73.6 \%)$ were $\mathrm{NTHi}$ and $16.5 \%, 6.6 \%$, and $3.3 \%$ were types b, $f$ (Hif), and e (Hie), respectively. There were 23 cases of pneumonia and $79 \%$ of these were due to NTHi. Pneumonia was more prevalent in adults ( $>14$ years) than in children ( $<14$ years): $25.9 \%$ versus $7.1 \%(p=0.03)$.

Berndsen, Erlendsdóttir, and Gottfredsson [124] reported on population based surveillance of invasive $H$. influenzae infections in Iceland from 1983 to 2008 . Since the introduction of the Hib conjugate vaccine, NTHi has become the most commonly isolated $H$. influenzae (40/59 isolates) from patients with pneumonia or bacteraemia, followed by Hif (14/59 isolates) which principally caused bacteraemic pneumonia. Underlying diseases were more common in both children and adults with NTHi infection compared to invasive Hib disease.

In England and Wales, the most common clinical presentation of invasive NTHi disease overall is pneumonia, which increases with age and occurs mainly in older adults, many of whom have underlying respiratory tract comorbidities [55] (Figure 2).

More recently, Torres et al [125] summarised the data available from 33 studies, published between 2005 and 2012, on the aetiology of CAP and/or antibiotic treatment in adults across Europe. Microbiological methods used were reported in 22 of the studies and were similar across all studies. The methods used included assessment of blood, sputum, urine (urinary antigen tests specifically for the detection of pneumococci and legionella) and pleural fluid samples, and less commonly, tracheobronchial, bronchoalveolar, transthoracic, and nasopharyngeal samples. Blood cultures were also performed in all 22 studies. S. pneumoniae was the most commonly isolated pathogen, being identified in $12.0-85.0 \%$ of patients within 19 studies, whilst $H$. influenzae was isolated in up to $29.4 \%$ of patients with 15 studies. $H$. influenzae ( $<65$ years: 4.1-6.4\%; $\geq 65$ years: $2.9-29.4 \%)$ and S. pneumoniae (<65 years: $20.9-28.0 \%$; $\geq 65$ years: $19.9-85.6 \%)$ were isolated more frequently in adults over the age of 65 years. The aetiology of CAP was similar in patients with and without COPD. Since these studies were conducted at a time when $\mathrm{Hib}$ immunisation of infants had been introduced across all of the participating countries, it is highly probable that these are cases of NTHi CAP, but again no details of serotyping results are given.

Peto et al [126] systematically reviewed 48 studies of adult CAP in Asia, excluding the Middle East, published between 1990 and 2012. From a total population of 10,423 , the

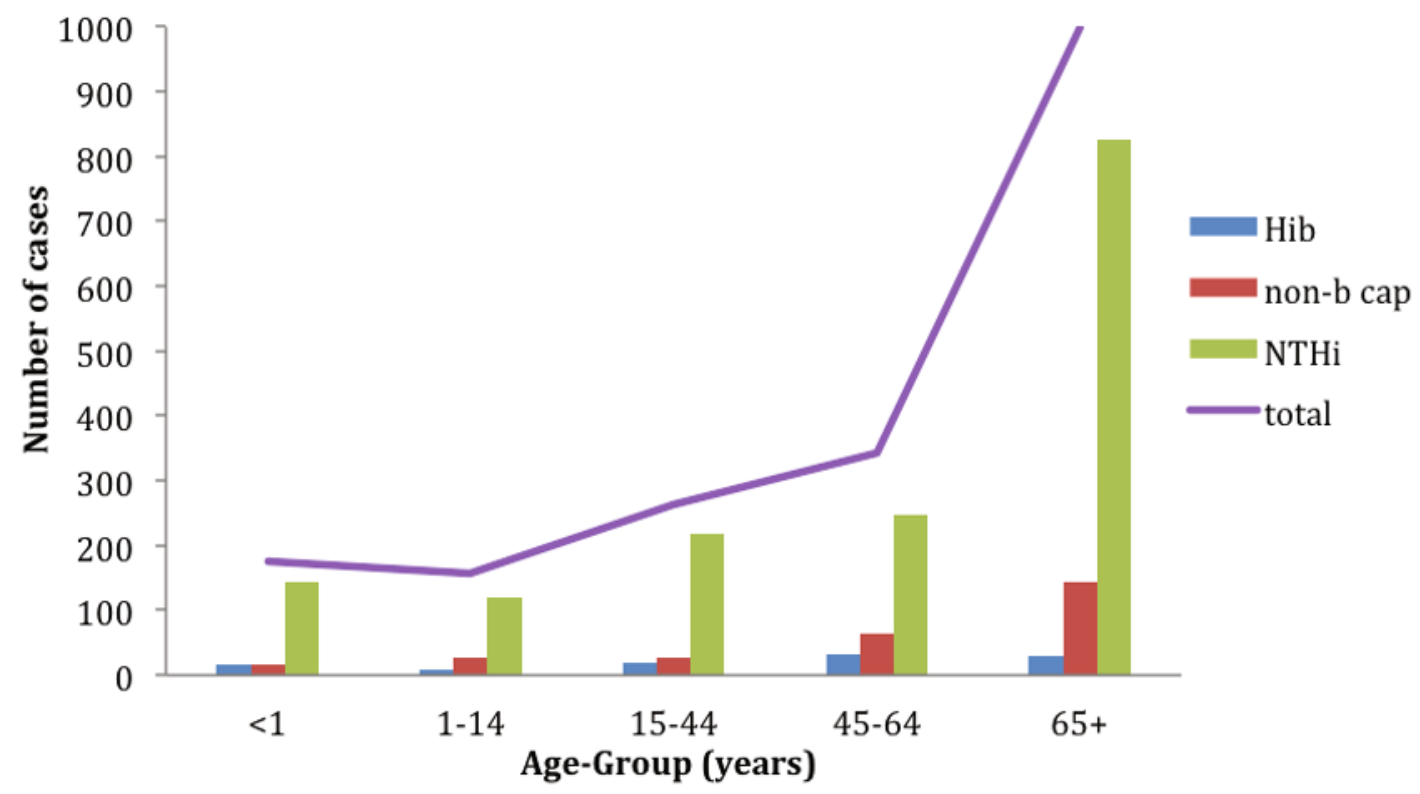

Figure 2 Cases of bacteraemic pneumonia in England and Wales, 2009-2012, by age group and serotype (Based on data from the Public Health England surveillance of Invasive Haemophilus influenzae infections. Available from https://www.gov.uk/government/ collections/Haemophilus-influenzae-guidance-data-and-analysis) 
overall rate of $H$. influenzae (serotype unspecified) CAP in Asia was $6.9 \%$ with rates varying from $19 \%$ in the Philippines, $10 \%$ in Japan and $9 \%$ in China, to $1 \%$ in India and South Korea. In most of the studies reviewed, 35-70\% of cases had no pathogen identified.

Impaired respiratory defense mechanisms may play a role in the pathogenesis of NTHi pneumonia in adults. Approximately $50 \%$ of healthy adults aspirate small amounts of oropharyngeal secretions during sleep, but the lower respiratory tract is protected from recurrent infections by effective mucociliary clearance, humoral, and cellular immune mechanisms, and coughing [120]. In elderly patients these defense mechanisms will be to an extent impaired and silent aspiration is an important factor in the development of CAP.

\subsubsection{Non-type b capsulated $H$. influenzae}

In countries where long-term surveillance of invasive $H$. influenzae disease has been conducted pre- and postHib conjugate vaccine implementation, there has been a small but steady increase in the incidence of invasive $H$. influenzae infections due to other serotypes of $H$. influenzae. The majority of these infections are due to NTHi (see Section 6.2.1), but there has also been a small increase in non-type $b$ capsulated strains. For example, in England and Wales during the period 2001 to 2010, a total of 1,275 invasive $H$. influenzae infections were reported, including 715 (56.1\%) NTHi, 69 (5.4\%) Hib, 99 (7.8\%) Hif, and 33 (2.6\%) Hie [127]. In 2001 there were 8 cases of invasive Hie infection, giving an adjusted annual estimated incidence of 0.021 (95\% Cl 0.009-0.040) per 100,000 population and 27 cases of Hif infection with an adjusted annual estimated incidence of 0.069 (95\% $\mathrm{Cl}$ 0.046-0.101) per 100,000 population. In 2010, there were 15 cases of Hie invasive infection, with an adjusted annual estimated incidence of 0.036 (95\% Cl 0.020-0.060) per 100,000 population and 52 cases of Hif infection, with an adjusted annual estimated incidence of 0.126 (95\% Cl 0.094-0.166) per 100,000 population. Ten cases ( $7 \mathrm{Hif}, 3 \mathrm{Hie}$ ) occurred in the first year of life and none of these infants presented with pneumonia. There were 13 cases in children aged 1-4 years ( $8 \mathrm{Hif}, 5 \mathrm{Hie}$ ), of whom 8 had underlying comorbidities. Four of these children had pneumonia. Over the same time period the number of cases of invasive NTHi infection increased from 220 in 2001 (adjusted annual estimated incidence 0.564 [95\% Cl 0.492-0.644] per 100,000 population) to 303 cases in 2010 (adjusted annual estimated incidence 0.736 [95\% Cl 0.656-0.824] per 100,000 population). Of the 132 Hif infections, 53 occurred in adults $>15$ years of age, and 52 occurred in adults aged $\geq 65$ years (based on data from the Public Health England surveillance of invasive $H$. influenzae infections. Available from https://www.gov. uk/government/collections/Haemophilus-influenzaeguidance-data-and-analysis). Pneumonia was the commonest presentation for both Hif and Hie, occurring in $53 / 83$ (63.9\%) adults with invasive Hif disease and 16/24 $(66.7 \%)$ adults with invasive Hie disease (Figure 3$)$. The majority of the patients had at least one comorbidity: the percentage with comorbidities rising from $70 \%$ for those aged $15-44$ years to $97 \%$ for those aged $>65$ years. The Case Fatality Ratio (CRF) for Hif pneumonia was $11.5 \%$ and

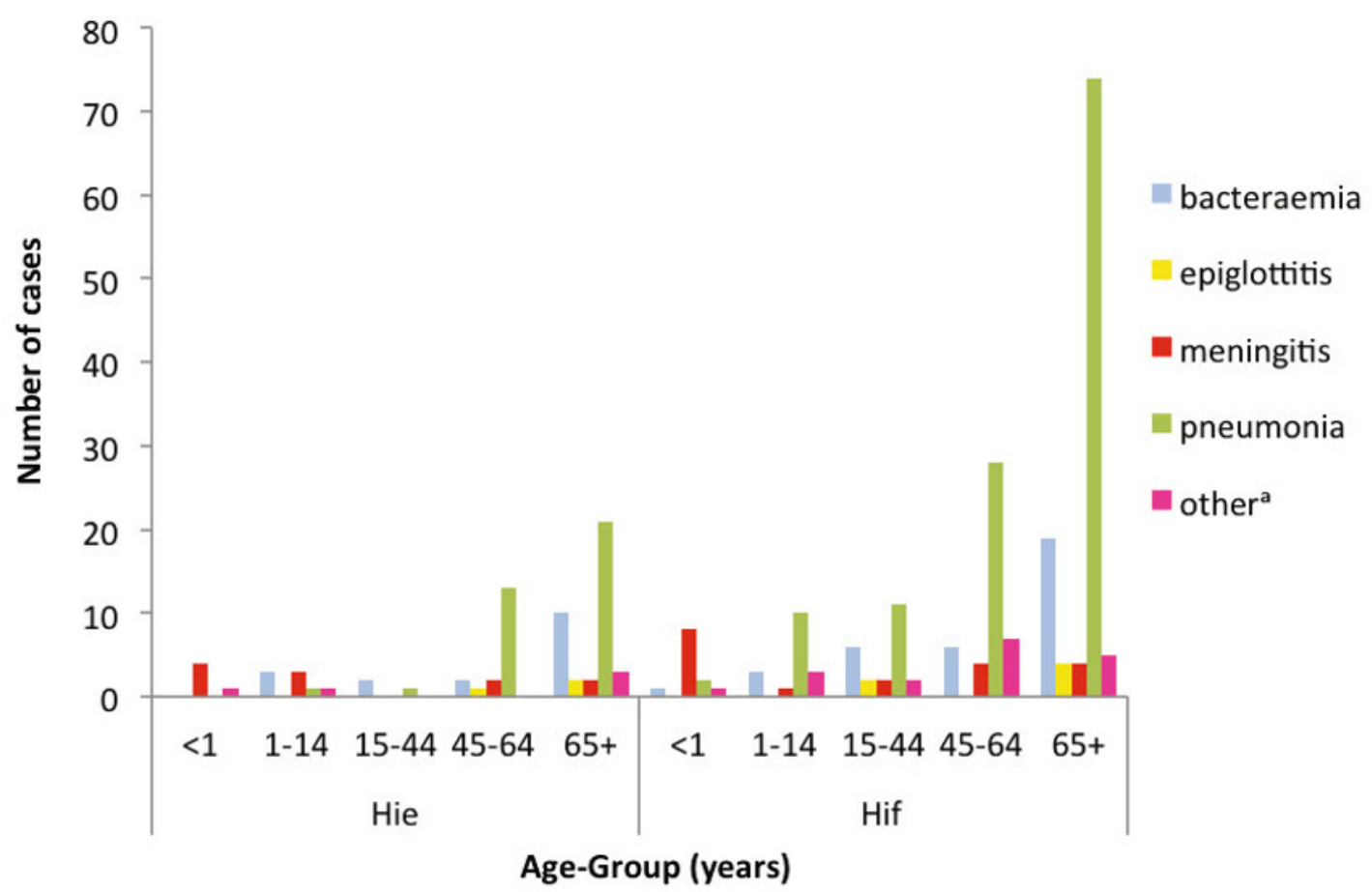

Figure 3 Cases of Haemophilus influenzae type e (Hie) and H. influenzae type f (Hif) bacteraemia in England and Wales, 2009-2012, by age group and clinical presentation (Based on data from the Public Health England surveillance of invasive $H$. influenzae infections. Available from https://www.gov.uk/government/collections/Haemophilus-influenzae-guidance-data-and-analysis)

${ }^{a}$ includes cases of invasive $H$. influenzae disease which presented with focal infections not listed above including cellulitis, cholecystitis, discitis, endocarditis, osteoarthritis, septic arthritis and genitourinary infections 
41.2\% for Hie pneumonia. Although Hie infections were less common than Hif, they appear to be more virulent with a higher infection-attributable case fatality rate even after adjustment for age and comorbidities. Invasive Hif and Hie disease in England and Wales appears to share many of the features of invasive NTHi disease, in that it tends to occur in older patients with underlying co-morbidities, commonly presents as pneumonia, and has a higher CFR compared to Hib infections in children $[127,128]$. Resman et al [129] reported a similar increase in both NTHi and Hif invasive infections in southern Sweden. In a retrospective study over the period 1997 to 2009, they identified 410 cases of invasive $H$. influenzae disease comprising $29 \mathrm{Hib}$, $44 \mathrm{Hif}, 1 \mathrm{Hie}$, and $191 \mathrm{NTHi}$. NTHi was predominant in all age groups including children $<5$ years of age. In 1998, the authors identified 8 cases of invasive NTHi disease and 2 cases of invasive Hif infection. In 2007, there were 35 NTHi invasive infections and 16 Hif invasive infections. A statistically significant increase in invasive disease by NTHi (Constant $=0.079,95 \% \mathrm{Cl} 0.046-0.111 ; p \leq 0.001$ ) and Hif (Constant $=0.023,95 \% \mathrm{Cl} 0.003-0.043, p<0.025$ ) was observed, whereas the incidence of Hib disease was unchanged during the study period. Of the invasive nontype $b$ infections, $70 \%$ presented with pneumonia and $59 \%$ of invasive Hif infections met the definition of severe sepsis or septic shock. The median age of Hif patients was 60 years and the CFR for Hif infections was $14 \%$. Interestingly, in this series, $68 \%$ of invasive Hif infections occurred in individuals without any pre-existing co-morbidities.

Hia has also been recognised as an important cause of invasive disease in some parts of the world [130], notably in indigenous populations in Canada and USA. The range of clinical presentations, including bacteraemic pneumonia, is analogous to that of $\mathrm{Hib}$ in the pre-vaccine era, with the exception that Hia does not appear to cause epiglottitis. As with Hie and Hif, adults are more likely to present with pneumonia, whereas children generally present with meningitis [131]. Interestingly, there is as yet no evidence of an increase in invasive disease due to non-type $b$ serotypes or NTHi in Australian Indigenous children [132].

\section{Discussion}

There is good evidence that all serotypes of $\mathrm{H}$. influenzae are respiratory pathogens and can cause CAP. NTHi are recognised as a common cause of CAP in adults, particularly those with underlying respiratory disease. The quality of data supporting a role of NTHi as a cause of paediatric CAP is more limited $[29,133]$. Data showed a clear role for NTHi in paediatric pneumonia in Papua New Guinea and The Gambia in the 1980s. However, this finding was generally not replicated in contemporaneous studies from the developed world. Although, De Schutter et al [61] have clearly demonstrated that with good quality specimens and appropriate conventional and molecular microbiological techniques, NTHi is indeed a significant cause of CAP in young European children.

There are a number of possible reasons for the disparity in the published studies. The generally held view is that NTHi is an uncommon cause of pneumonia, except in adults with COPD. It is therefore possible that if NTHi are isolated from respiratory samples they may simply be dismissed as contaminants rather than the organism causing the infection. The routine bacteriological and blood culture methods used may be inappropriate for the recovery of a fastidious organism like $H$. influenzae, and compared to NTHi, is less likely to invade the blood stream. It is of note that the studies from Papua New Guinea, Pakistan and The Gambia [100-104], which employed lung aspirates, did detect NTHi as a significant cause of paediatric pneumonia.

Many of the published studies do not give details of serotyping of strains of $H$. influenzae, and prior to the introduction of Hib conjugate vaccines, Haemophilus pneumonia was probably assumed to be due to Hib. Conventional serotyping is less reliable than PCRbased molecular typing. NTHi invade the blood stream less readily than $\mathrm{Hib}$ and so would represent a small proportion in any series of bacteraemic pneumonias. Non-bacteraemic pneumonia is a mucosal infection which is often polymicrobial, with a bacterial infection following a viral infection. Therefore, the role of NTHi in non-bacteraemic pneumonia could be under-reported or overlooked. NTHi are well-recognised as a major cause of upper respiratory tract infections including otitis media and sinusitis. It therefore seems highly probable that this organism is capable of causing lower respiratory tract infections, possibly by contiguous spread from the upper airway. A preceding viral upper respiratory tract infection may facilitate the development of lower airways infection, including CAP (see Section 3.1). There are no data indicating whether different strains of NTHi are involved in asymptomatic colonisation and infection, but whole genome analysis of carriage strains and strains isolated from lower respiratory tract infections may identify adaptive features that could be applied as diagnostic tools.

In order to determine the extent to which $H$. influenzae, including NTHi, is a significant cause of bacteraemic and non-bacteraemic paediatric and adult CAP, a systematic study should ideally be undertaken using the most appropriate sampling techniques and applying the best methods of testing to those samples. In children where BAL or lung taps are not performed and who cannot expectorate sputum, it may be that an algorithmic approach is necessary, using standardised methodologies, a range of biomarkers, possibly including metabolic analysis of urine, and quantitative RT-PCR (with appropriate primers to differentiate capsular serotypes, NTHi and $H$. haemolyticus) on nasopharyngeal swabs, serum and blood cultures. Again, this is not entirely straightforward, since neither the presence nor the density of NTHi in nasopharyngeal swabs is correlated with lower respiratory tract NTHi clinical infection (Heidi Smith-Vaughan, Personal Communication, 24 February 2015). Since the majority of cases of CAP are not investigated at all, systematic studies utilising improved case ascertainment, standardised case definitions, diagnostic and sampling techniques, coupled 
with modern molecular diagnostic techniques could provide an indication of the likely proportion of CAP due to NTHi in any given age group [134].

\section{Conclusion}

NTHi is a well-recognised cause of mucosal infections such as otitis media, sinusitis, and exacerbations of COPD. With the use of sophisticated diagnostic techniques and appropriate molecular identification, it is clear that NTHi are also an important but under-recognised cause of CAP in both children and adults. In countries where Hib has been virtually eliminated by the use of the Hib conjugate vaccine, NTHi are by far the most common cause of $H$. influenzae infections across all age groups, including pneumonia. Improved surveillance of bacteraemic and non-bacteraemic CAP is needed to fully understand the role of NTHi in this important group of infections.

\section{Acknowledgements}

The author would like to thank Professor Allan Cripps, Griffith University, Australia, for his encouragement and support in preparing this review, and Heidi Smith-Vaughan, Charles Darwin University and Griffith University, Australia, for her helpful comments.

Funding: The author has no funding to report.

Competing interests: The author declares to have received support from GlaxoSmithKline, Merck Sharp Dome, and Pfizer to attend and present at conferences, scientific meetings and advisory boards

Provenance and peer review: Commissioned; no funding has been requested or received by the author for the preparation of the manuscript; externally peer reviewed.

Copyright: This is an open-access article distributed under the terms of the Creative Commons Attribution License, which permits unrestricted use, distribution, and reproduction in any medium, provided the original author and source are credited.

\section{References}

1. Lozano R, Naghavi M, Foreman K, Lim S, Shibuya K, Aboyans $V$ et al. Global and regional mortality from 235 causes of death for 20 age groups in 1990 and 2010: a systematic analysis for the Global Burden of Disease Study 2010. Lancet 2012;380:2095-128. http://dx.doi.org/10.1016/ S0140-6736(12)61728-0. PMID:23245604

2. Rudan I, O'Brien KL, Nair H, Liu L, Theodoratou E, Qazi S et al.; Child Health Epidemiology Reference Group (CHERG). Epidemiology and etiology of childhood pneumonia in 2010: estimates of incidence, severe morbidity, mortality, underlying risk factors and causative pathogens for 192 countries. J Glob Health 2013;3:010401. PMID:23826505

3. Walker CL, Rudan I, Liu L, Nair H, Theodoratou E, Bhutta ZA et al. Global burden of childhood pneumonia and diarrhoea. Lancet 2013;381:1405-16. http://dx.doi.org/10.1016/
S0140-6736(13)60222-6. PMID:23582727

4. Nair H, Simões EA, Rudan I, Gessner BD, Azziz-Baumgartner $E$, Zhang JS et al.; Severe Acute Lower Respiratory Infections Working Group. Global and regional burden of hospital admissions for severe acute lower respiratory infections in young children in 2010: a systematic analysis. Lancet 2013;381:1380-90.http://dx.doi.org/10.1016/S01406736(12)61901-1. PMID:23369797

5. Valery PC, Torzillo PJ, Mulholland K, Boyce NC, Purdie DM, Chang AB. Hospital-based case-control study of bronchiectasis in indigenous children in Central Australia. Pediatr Infect Dis J 2004;23:902-8. http://dx.doi. org/10.1097/01.inf.0000142508.33623.2f. PMID:15602188

6. Puchalski Ritchie LM, Howie SR, Arenovich T, Cheung YB, Weber $\mathrm{M}$, Moore $\mathrm{S}$ et al. Long-term morbidity from severe pneumonia in early childhood in The Gambia, West Africa: a follow-up study. Int J Tuberc Lung Dis 2009;13:527-32. PMID:19335961

7. Chang $A B$, Byrnes $C A$, Everard ML. Diagnosing and preventing chronic suppurative lung disease (CSLD) and bronchiectasis. Paediatr Respir Rev 2011;12:97-103. http:// dx.doi.org/10.1016/j.prrv.2010.10.008. PMID:21458737

8. Steinfort DP, Brady S, Weisinger HS, Einsiedel L. Bronchiectasis in Central Australia: a young face to an old disease. Respir Med 2008;102:574-8. http://dx.doi. org/10.1016/j.rmed.2007.11.007. PMID:18086522

9. Woodhead M. Community-acquired pneumonia in Europe: causative pathogens and resistance patterns. Eur Respir J Suppl 2002;36 Suppl 36):20s-7s.http://dx.doi.org/10.1183 /09031936.02.00702002 PMID:12168744

10. Peltola H. Worldwide Haemophilus influenzae type b disease at the beginning of the 21st century: global analysis of the disease burden 25 years after the use of the polysaccharide vaccine and a decade after the advent of conjugates. Clin Microbiol Rev 2000;13:302-http://dx.doi.org/10.1128/ CMR.13.2.302-317.2000. PMID:10756001

11. Pittman M. Variation and type specificity in the bacterial species Haemophilus influenzae. J Exp Med 1931;53:471-92. http://dx.doi.org/10.1084/jem.53.4.471. PMID:19869858

12. McCrea KW, Xie J, LaCross N, Patel M, Mukundan D, Murphy TF et al. Relationships of nontypeable Haemophilus influenzae strains to hemolytic and nonhemolytic Haemophilus haemolyticus strains. J Clin Microbiol 2008;46:406-16. http://dx.doi.org/10.1128/JCM.0183207. PMID:18039799

13. Binks MJ, Temple B, Kirkham LA, Wiertsema SP, Dunne $E M$, Richmond PC et al. Molecular surveillance of true nontypeable Haemophilus influenzae: an evaluation of PCR screening assays. PLoS ONE 2012;7:e34083. http://dx.doi. org/10.1371/journal.pone.0034083. PMID:22470516

14. Zhu B, Xiao D, Zhang H, Zhang Y, Gao Y, Xu L et al. MALDITOF MS distinctly differentiates nontypable Haemophilus influenzae from Haemophilus haemolyticus. PLOS ONE 2013;8:e56139. http://dx.doi.org/10.1371/journal. pone.0056139. PMID:23457514

15. Falla TJ, Crook DW, Brophy LN, Maskell D, Kroll JS, Moxon ER. PCR for capsular typing of Haemophilus influenzae. J Clin Microbiol 1994;32:2382-6. PMID:7814470

16. Howard AJ, Dunkin KT, Millar GW. Nasopharyngeal carriage 
and antibiotic resistance of Haemophilus influenzae in healthy children. Epidemiol Infect 1988;100:193-203. http://dx.doi.org/10.1017/S0950268800067327. PMID:3258568

17. Gratten M, Gratten H, Poli A, Carrad E, Raymer M, Koki G. Colonisation of Haemophilus influenzae and Streptococcus pneumoniae in the upper respiratory tract of neonates in Papua New Guinea: primary acquisition, duration of carriage, and relationship to carriage in mothers. Biol Neonate 1986;50:114-20.http://dx.doi.org/10.1159/000242576. PMID:3489488

18. Watson K, Carville K, Bowman J, Jacoby P, Riley TV, Leach AJ et al.; Kalgoorlie Otitis Media Research Project Team. Upper respiratory tract bacterial carriage in Aboriginal and non-Aboriginal children in a semi-arid area of Western Australia. Pediatr Infect Dis J 2006;25:782-90. http://dx.doi.org/10.1097/01.inf.0000232705.49634.68. PMID:16940834

19. Faden H, Duffy L, Williams A, Krystofik DA, Wolf J. Epidemiology of nasopharyngeal colonization with nontypeable Haemophilus influenzae in the first 2 years of life. J Infect Dis 1995;172:132-5. http://dx.doi.org/10.1093/ infdis/172.1.132. PMID:7797903

20. Farjo RS, Foxman B, Patel MJ, Zhang L, Pettigrew MM, McCoy SI et al. Diversity and sharing of Haemophilus influenzae strains colonizing healthy children attending day-care centers. Pediatr Infect Dis J 2004;23:41-6. http://dx.doi.org/10.1097/01.inf.0000106981.89572.d1. PMID:14743045

21. Peerbooms PG, Engelen MN, Stokman DA, van Benthem $\mathrm{BH}$, van Weert ML, Bruisten SM et al. Nasopharyngeal carriage of potential bacterial pathogens related to day care attendance, with special reference to the molecular epidemiology of Haemophilus influenzae. J Clin Microbiol 2002;40:2832-6. http://dx.doi.org/10.1128/ JCM.40.8.2832-2836.2002. PMID:12149338

22. Mackenzie GA, Leach AJ, Carapetis JR, Fisher J, Morris PS. Epidemiology of nasopharyngeal carriage of respiratory bacterial pathogens in children and adults: cross-sectional surveys in a population with high rates of pneumococcal disease. BMC Infect Dis 2010;10:304. http://dx.doi. org/10.1186/1471-2334-10-304. PMID:20969800

23. Shak JR, Cremers AJ, Gritzfeld JF, de Jonge MI, Hermans PW, Vidal JE et al. Impact of experimental human pneumococcal carriage on nasopharyngeal bacterial densities in healthy adults. PLoS ONE 2014;9:e98829. http://dx.doi. org/10.1371/journal.pone.0098829. PMID:24915552

24. Murphy TF. Haemophilus influenzae in chronic bronchitis. Semin Respir Infect 2000;15:41-51. http://dx.doi. org/10.1053/srin.2000.0150041. PMID:10749549

25. Bandi V, Apicella MA, Mason E, Murphy TF, Siddiqi A, Atmar $\mathrm{RL}$ et al. Nontypeable Haemophilus influenzae in the lower respiratory tract of patients with chronic bronchitis. Am J Respir Crit Care Med 2001;164:2114-9. http://dx.doi. org/10.1164/ajrccm.164.11.2104093. PMID:11739144

26. Papi $A$, Bellettato $C M$, Braccioni F, Romagnoli $M$, Casolari $\mathrm{P}$, Caramori $\mathrm{G}$ et al. Infections and airway inflammation in chronic obstructive pulmonary disease severe exacerbations. Am J Respir Crit Care Med 2006;173:111421.http://dx.doi.org/10.1164/rccm.200506-8590C.

\section{PMID:16484677}

27. Rosell A, Monsó E, Soler N, Torres F, Angrill J, Riise G et al. Microbiologic determinants of exacerbation in chronic obstructive pulmonary disease. Arch Intern Med 2005;165:891-7. http://dx.doi.org/10.1001/ archinte.165.8.891. PMID:15851640

28. Garcha DS, Thurston SJ, Patel AR, Mackay AJ, Goldring JJ, Donaldson GC et al. Changes in prevalence and load of airway bacteria using quantitative PCR in stable and exacerbated COPD. Thorax 2012;67:1075-80. http://dx.doi. org/10.1136/thoraxjnl-2012-201924. PMID:22863758

29. Murphy TF, Faden H, Bakaletz LO, Kyd JM, Forsgren A, Campos J et al. Nontypeable Haemophilus influenzae as a pathogen in children. Pediatr Infect Dis J 2009;28:438. http://dx.doi.org/10.1097/INF.0b013e318184dba2. PMID:19057458

30. Murphy TF, Sethi S, Klingman KL, Brueggemann AB, Doern GV. Simultaneous respiratory tract colonization by multiple strains of nontypeable Haemophilus influenzae in chronic obstructive pulmonary disease: implications for antibiotic therapy. J Infect Dis 1999;180:404-9. http://dx.doi. org/10.1086/314870. PMID:10395856

31. Sethi S, Evans N, Grant BJ, Murphy TF. New strains of bacteria and exacerbations of chronic obstructive pulmonary disease. N Engl J Med 2002;347:465-71. http:// dx.doi.org/10.1056/NEJMoa012561. PMID:12181400

32. Wilkinson TM, Hurst JR, Perera WR, Wilks M, Donaldson GC, Wedzicha JA. Effect of interactions between lower airway bacterial and rhinoviral infection in exacerbations of COPD. Chest 2006;129:317-24. http://dx.doi.org/10.1378/ chest.129.2.317. PMID:16478847

33. Sethi S, Wrona C, Grant BJ, Murphy TF. Strain-specific immune response to Haemophilus influenzae in chronic obstructive pulmonary disease. Am J Respir Crit Care Med 2004;169:448-53. http://dx.doi.org/10.1164/ rccm.200308-11810C. PMID:14597486

34. Ladhani S, Neely F, Heath PT, Nazareth B, Roberts R, Slack MP et al. Recommendations for the prevention of secondary Haemophilus influenzae type b (Hib) disease. J Infect 2009;58:3-14. http://dx.doi.org/10.1016/j. jinf.2008.10.007. PMID:19152980

35. Pfeiffer R. I.-Preliminary Communication on the Exciting causes of Influenza. BMJ 1892;1:128. http://dx.doi. org/10.1136/bmj.1.1620.128. PMID:20753501

36. Pfeiffer R F J. Die Aetiologie der Influenza. Z Hyg Infektionskr 1893;13:357-86. Available from: http://dx.doi. org/10.1007/BF02284284.

37. Kristensen $M$. Investigations into the occurrence and classification of the haemoglobinophilic bacteria. Levin and Munksgaard, Copenhagen 1922 (quoted in Turk DC, May JR.Haemophilus influenzae: its clinical importance. The English Universities Press Ltd, London 1967p1)

38. Smith W, Andrewes $\mathrm{CH}$, Laidlaw PP. A Virus Obtained from Influenza Patients. Lancet 1933;2:66-8. http://dx.doi. org/10.1016/S0140-6736(00)78541-2.

39. McCullers JA. The co-pathogenesis of influenza viruses with bacteria in the lung. Nat Rev Microbiol 2014;12:252-62. http://dx.doi.org/10.1038/nrmicro3231. PMID:24590244

40. Wilkinson TM, Hurst JR, Perera WR, Wilks M, Donaldson GC, Wedzicha JA. Effect of interactions between lower 
airway bacterial and rhinoviral infection in exacerbations of COPD. Chest 2006;129:317-24. http://dx.doi.org/10.1378/ chest.129.2.317. PMID:16478847

41. Bosch AA, Biesbroek G, Trzcinski K, Sanders EA, Bogaert $D$. Viral and bacterial interactions in the upper respiratory tract. PLoS Pathog 2013;9:e1003057. http://dx.doi. org/10.1371/journal.ppat.1003057. PMID:23326226

42. Mina MJ, Klugman KP. The role of influenza in the severity and transmission of respiratory bacterial disease. Lancet Respir Med 2014;2:750-63. http://dx.doi.org/10.1016/ S2213-2600(14)70131-6. PMID:25131494

43. Bogaert D, De Groot R, Hermans PW. Streptococcus pneumoniae colonisation: the key to pneumococcal disease. Lancet Infect Dis 2004;4:144-54. http://dx.doi. org/10.1016/S1473-3099(04)00938-7. PMID:14998500

44. Suzuki K, Bakaletz LO. Synergistic effect of adenovirus type 1 and nontypeable Haemophilus influenzae in a chinchilla model of experimental otitis media. Infect Immun 1994;62:1710-8. PMID:8168932

45. Sajjan U, Wang Q, Zhao Y, Gruenert DC, Hershenson MB. Rhinovirus disrupts the barrier function of polarized airway epithelial cells. Am J Respir Crit Care Med 2008;178:127181. http://dx.doi.org/10.1164/rccm.200801-1360C. PMID:18787220

46. Avadhanula V, Rodriguez CA, Devincenzo JP, Wang $\mathrm{Y}$, Webby RJ, Ulett GC et al. Respiratory viruses augment the adhesion of bacterial pathogens to respiratory epithelium in a viral species- and cell type-dependent manner. J Virol 2006;80:1629-36. http://dx.doi.org/10.1128/ JVI.80.4.1629-1636.2006. PMID:16439519

47. Gulraiz F, Bellinghausen C, Bruggeman CA, Stassen FR. Haemophilus influenzae increases the susceptibility and inflammatory response of airway epithelial cells to viral infections. FASEB J 2015;29:849-58. http://dx.doi. org/10.1096/fj.14-254359. PMID:25411435

48. McNamee LA, Harmsen AG. Both influenza-induced neutrophil dysfunction and neutrophil-independent mechanisms contribute to increased susceptibility to a secondary Streptococcus pneumoniae infection. Infect Immun 2006;74:6707-21. http://dx.doi.org/10.1128/ IAI.00789-06. PMID:16982840

49. Shahangian A, Chow EK, Tian X, Kang JR, Ghaffari A, Liu SY et al. Type I IFNs mediate development of postinfluenza bacterial pneumonia in mice. J Clin Invest 2009;119:191020. http://dx.doi.org/10.1172/JCI35412. PMID:19487810

50. Sun K, Metzger DW. Inhibition of pulmonary antibacterial defense by interferon-gamma during recovery from influenza infection. Nat Med 2008;14:558-64. http:// dx.doi.org/10.1038/nm1765. PMID:18438414

51. Didierlaurent A, Goulding J, Patel S, Snelgrove R, Low L, Bebien $M$ et al. Sustained desensitization to bacterial Toll-like receptor ligands after resolution of respiratory influenza infection. J Exp Med 2008;205:323-9. http:// dx.doi.org/10.1084/jem.20070891. PMID:18227219

52. Anderson EC, Begg NT, Crawshaw SC, Hargreaves RM, Howard AJ, Slack MP. Epidemiology of invasive Haemophilus influenzae infections in England and Wales in the prevaccination era (1990-2). Epidemiol Infect 1995;115:89100. http://dx.doi.org/10.1017/S0950268800058155. PMID:7641841
53. Peltola H. Worldwide Haemophilus influenzae type b disease at the beginning of the 21st century: global analysis of the disease burden 25 years after the use of the polysaccharide vaccine and a decade after the advent of conjugates. Clin Microbiol Rev 2000;13:302-17. http://dx.doi.org/10.1128/ CMR.13.2.302-317.2000. PMID:10756001

54. Watt JP, Wolfson LJ, O'Brien KL, Henkle E, Deloria-Knoll $\mathrm{M}, \mathrm{McC}$ all $\mathrm{N}$ et al.; Hib and Pneumococcal Global Burden of Disease Study Team. Burden of disease caused by Haemophilus influenzae type $b$ in children younger than 5 years: global estimates. Lancet 2009;374:903-11. http://dx.doi.org/10.1016/S0140-6736(09)61203-4. PMID:19748399

55. Van Eldere J, Slack MPE, Ladhani S, Cripps AW. Non-typeable Haemophilus influenzae: an under-recognised pathogen. Lancet Infect Dis 2014;S1473-3099(14):70734-0. http:// dx.doi.org/10.1016/S1473-3099

56. Knoll MD, Moïsi JC, Muhib FB, Wonodi CB, Lee EH, Grant $L$ et al.; PneumoADIP-Sponsored Surveillance Investigators. Standardizing surveillance of pneumococcal disease. Clin Infect Dis 2009;48 Suppl 2:S37-48. http://dx.doi. org/10.1086/596480. PMID:19191618

57. Bartlett JG. Diagnostic tests for agents of communityacquired pneumonia. Clin Infect Dis 2011;52 Suppl 4:S296304. http://dx.doi.org/10.1093/cid/cir045. PMID:21460288

58. Bartlett JG, Finegold SM. Bacteriology of expectorated sputum with quantitative culture and wash technique compared to transtracheal aspirates. Am Rev Respir Dis 1978;117:1019-27. PMID:352206

59. Lahti E, Peltola V, Waris M, Virkki R, Rantakokko-Jalava K, Jalava $J$ et al. Induced sputum in the diagnosis of childhood community-acquired pneumonia. Thorax 2009;64:2527.http://dx.doi.org/10.1136/thx.2008.099051. PMID:19052043

60. Efrati O, Sadeh-Gornik U, Modan-Moses D, Barak A, Szeinberg A, Vardi $A$ et al. Flexible bronchoscopy and bronchoalveolar lavage in pediatric patients with lung disease. Pediatr Crit Care Med 2009;10:80-4. http://dx.doi. org/10.1097/PCC.0b013e31819372ea. PMID:19057431

61. De Schutter I, De Wachter E, Crokaert F, Verhaegen J, Soetens $\mathrm{O}$, Piérard $\mathrm{D}$ et al. Microbiology of bronchoalveolar lavage fluid in children with acute nonresponding or recurrent community-acquired pneumonia: identification of nontypeable Haemophilus influenzae as a major pathogen. Clin Infect Dis 2011;52:1437-44. http://dx.doi. org/10.1093/cid/cir235. PMID:21628484

62. Silverman $M$, Stratton D, Diallo A, Egler LJ. Diagnosis of acute bacterial pneumonia in Nigerian children. Value of needle aspiration of lung of countercurrent immunoelectrophoresis. Arch Dis Child 1977;52:925-31. http://dx.doi.org/10.1136/adc.52.12.925. PMID:343723

63. Barnes DJ, Naraqi S, Igo JD. The role of percutaneous lung aspiration in the bacteriological diagnosis of pneumonia in adults. Aust N Z J Med 1988;18:754-7. http://dx.doi. org/10.1111/j.1445-5994.1988.tb00174.x. PMID:3266552

64. Scott JA, Hall AJ. The value and complications of percutaneous transthoracic lung aspiration for the etiologic diagnosis of community-acquired pneumonia. Chest 1999;116:1716-32. http://dx.doi.org/10.1378/ chest.116.6.1716. PMID:10593800 
65. Vuori-Holopainen E, Peltola H. Reappraisal of lung tap: review of an old method for better etiologic diagnosis of childhood pneumonia. Clin Infect Dis 2001;32:715-26. http://dx.doi.org/10.1086/319213. PMID:11229839

66. Vuori-Holopainen E, Salo E, Saxén H, Hedman K, Hyypiä $\mathrm{T}$, Lahdenperä $\mathrm{R}$ et al. Etiological diagnosis of childhood pneumonia by use of transthoracic needle aspiration and modern microbiological methods. Clin Infect Dis 2002;34:583-90.http://dx.doi.org/10.1086/338642. PMID:11803504

67. Rello J, Lisboa T, Lujan M, Gallego M, Kee C, Kay I et al.; DNA-Neumococo Study Group. Severity of pneumococcal pneumonia associated with genomic bacterial load. Chest 2009;136:832-40. http://dx.doi.org/10.1378/ chest.09-0258. PMID:19433527

68. Azzari C, Moriondo M, Indolfi G, Massai C, Becciolini L, de Martino $\mathrm{M}$ et al. Molecular detection methods and serotyping performed directly on clinical samples improve diagnostic sensitivity and reveal increased incidence of invasive disease by Streptococcus pneumoniae in Italian children. J Med Microbiol 2008;57:1205-12. http://dx.doi. org/10.1099/jmm.0.2008/000935-0. PMID:18809546

69. Peters RP, de Boer RF, Schuurman T, Gierveld S, KooistraSmid M, van Agtmael MA et al. Streptococcus pneumoniae DNA load in blood as a marker of infection in patients with community-acquired pneumonia. J Clin Microbiol 2009;47:3308-12. http://dx.doi.org/10.1128/JCM.0107109. PMID:19675218

70. Lai JY, Binks MJ, Kaestli M, Leach AJ, Smith-Vaughan HC. Potential use of serum based quantitative real-time PCR for the detection of pneumonia pathogens in a densely colonised population. pneumonia 2012;1:7-10. http:// dx.doi.org/10.15172/pneu.2012.1/209

71. Caliendo AM. Multiplex PCR and emerging technologies for the detection of respiratory pathogens. Clin Infect Dis 2011;52 Suppl 4:S326-30. http://dx.doi.org/10.1093/cid/ cir047. PMID:21460291

72. Bhat $N, O^{\prime}$ Brien KL, Karron RA, Driscoll AJ, Murdoch DR; Pneumonia Methods Working Group. Use and evaluation of molecular diagnostics for pneumonia etiology studies. Clin Infect Dis 2012;54 Suppl 2:S153-8. http://dx.doi. org/10.1093/cid/cir1060. PMID:22403230

73. Juvén $T$, Mertsola J, Waris $M$, Leinonen $M$, Meurman $\mathrm{O}$, Roivainen $\mathrm{M}$ et al. Etiology of community-acquired pneumonia in 254 hospitalized children. Pediatr Infect Dis J 2000;19:293-8. http://dx.doi.org/10.1097/00006454200004000-00006. PMID:10783017

74. Lim WS, Macfarlane JT, Boswell TC, Harrison TG, Rose $D$, Leinonen $M$ et al. Study of community acquired pneumonia aetiology (SCAPA) in adults admitted to hospital: implications for management guidelines. Thorax 2001;56:296-301. http://dx.doi.org/10.1136/ thorax.56.4.296. PMID:11254821

75. Johansson N, Kalin M, Tiveljung-Lindell A, Giske CG, Hedlund J. Etiology of community-acquired pneumonia: increased microbiological yield with new diagnostic methods. Clin Infect Dis 2010;50:202-9. http://dx.doi. org/10.1086/648678. PMID:20014950

76. Johansson N, Kalin M, Hedlund J. Clinical impact of combined viral and bacterial infection in patients with community-acquired pneumonia. Scand J Infect Dis 2011;43:609-15. http://dx.doi.org/10.3109/00365548.201 1.570785. PMID:21466255

77. Niederman MS. Biological markers to determine eligibility in trials for community-acquired pneumonia: a focus on procalcitonin. Clin Infect Dis 2008;47 Suppl 3:S127-32. http://dx.doi.org/10.1086/591393. PMID:18986278

78. Slupsky CM, Rankin KN, Fu H, Chang D, Rowe BH, Charles PG et al. Pneumococcal pneumonia: potential for diagnosis through a urinary metabolic profile. J Proteome Res 2009;8:5550-8. http://dx.doi.org/10.1021/pr9006427. PMID:19817432

79. Slupsky CM. Nuclear magnetic resonance-based analysis of urine for the rapid etiological diagnosis of pneumonia. Expert Opin Med Diagn 2011;5:63-73. http://dx.doi.org/10 .1517/17530059.2011.537653. PMID:23484477

80. Laiakis EC, Morris GA, Fornace AJ, Howie SR. Metabolomic analysis in severe childhood pneumonia in the Gambia, West Africa: findings from a pilot study. PLOS ONE 2010;5:e12655. http://dx.doi.org/10.1371/journal. pone.0012655. PMID:20844590

81. Cassiday L. Diagnosing pneumonia with urinary metabolomics. J Proteome Res 2009;8:5409-10. http:// dx.doi.org/10.1021/pr9009832. PMID:19899780

82. Lim WS, Baudouin SV, George RC, Hill AT, Jamieson C, Le Jeune I et al.; Pneumonia Guidelines Committee of the BTS Standards of Care Committee. BTS guidelines for the management of community acquired pneumonia in adults: update 2009. Thorax 2009;64 Suppl 3:iii1-55. http://dx.doi. org/10.1136/thx.2009.121434. PMID:19783532

83. Harris M, Clark J, Coote N, Fletcher P, Harnden A, McKean M et al.; British Thoracic Society Standards of Care Committee. British Thoracic Society guidelines for the management of community acquired pneumonia in children: update 2011. Thorax 2011;66 Suppl 2:ii1-23. http://dx.doi.org/10.1136/ thoraxjnl-2011-200598. PMID:21903691

84. Mandell LA, Wunderink RG, Anzueto A, Bartlett JG, Campbell GD, Dean NC et al.; Infectious Diseases Society of America; American Thoracic Society. Infectious Diseases Society of America/American Thoracic Society consensus guidelines on the management of community-acquired pneumonia in adults. Clin Infect Dis 2007;44 Suppl 2:S27-72. http:// dx.doi.org/10.1086/511159. PMID:17278083

85. Wunderink RG, Waterer GW. Clinical practice. Communityacquired pneumonia. N Engl J Med 2014;370:543-51. http:// dx.doi.org/10.1056/NEJMcp1214869. PMID:24499212

86. World Health Organisation Pneumonia Vaccine Trial Investigators Group. Standardization of interpretation of chest radiographs for the diagnosis of pneumonia in children. WHO/V\&B/01.35.Geneva:WHO;2001

87. Cherian T, Mulholland EK, Carlin JB, Ostensen H, Amin R, de Campo $M$ et al. Standardized interpretation of paediatric chest radiographs for the diagnosis of pneumonia in epidemiological studies. Bull World Health Organ 2005;83:353-9. PMID:15976876

88. Williams GJ, Macaskill P, Kerr M, Fitzgerald DA, Isaacs D, Codarini $\mathrm{M}$ et al. Variability and accuracy in interpretation of consolidation on chest radiography for diagnosing pneumonia in children under 5 years of age. Pediatr Pulmonol 2013;48:1195-200. http://dx.doi.org/10.1002/ 
ppul.22806. PMID:23997040

89. Esposito S, Principi N. Unsolved problems in the approach to pediatric community-acquired pneumonia. Curr Opin Infect Dis 2012;25:286-91. http://dx.doi.org/10.1097/ QCO.0b013e328352b60c. PMID:22421754

90. Obaro SK, Madhi SA. Bacterial pneumonia vaccines and childhood pneumonia: are we winning, refining, or redefining? Lancet Infect Dis 2006;6:150-61. http://dx.doi. org/10.1016/S1473-3099(06)70411-X. PMID:16500596

91. Schell RF, Le Frock JL, Babu JP, Robinson DB. Recovery of Haemophilus influenzae from twenty-three blood culture media. J Clin Microbiol 1979;9:84-7. PMID:311778

92. Selva L, Benmessaoud R, Lanaspa M, Jroundi I, Moraleda C, Acacio $S$ et al. Detection of Streptococcus pneumoniae and Haemophilus influenzae type $b$ by real-time PCR from dried blood spot samples among children with pneumonia: a useful approach for developing countries. PLoS ONE 2013;8:e76970. http://dx.doi.org/10.1371/journal. pone.0076970. PMID:24116190

93. Mulholland EK. Use of vaccine trials to estimate burden of disease. J Health Popul Nutr 2004;22:257-67. PMID:15609778

94. Mulholland K, Hilton S, Adegbola R, Usen S, Oparaugo $A$, Omosigho $C$ et al. Randomised trial of Haemophilus influenzae type-b tetanus protein conjugate vaccine [corrected] for prevention of pneumonia and meningitis in Gambian infants. Lancet 1997;349:1191-7. http://dx.doi. org/10.1016/S0140-6736(96)09267-7. PMID:9130939

95. Ladhani S, Slack MP, Heath PT, Ramsay ME. Changes in ascertainment of $\mathrm{Hib}$ and its influence on the estimation of disease incidence in the United Kingdom. Epidemiol Infect 2007;135:861-7. http://dx.doi.org/10.1017/ S0950268806007382. PMID:17092395

96. Collins S, Ramsay M, Campbell H, Slack MP, Ladhani SN. Invasive Haemophilus influenzae type b disease in England and Wales: who is at risk after 2 decades of routine childhood vaccination? Clin Infect Dis 2013;57:1715-21. http://dx.doi.org/10.1093/cid/cit579. PMID:24076970

97. Singh V, Aneja S. Pneumonia - management in the developing world. Paediatr Respir Rev 2011;12:52-9. http:// dx.doi.org/10.1016/j.prrv.2010.09.011. PMID:21172676

98. Ladhani S, Ramsay ME, Chandra M, Slack MP; EU-IBIS. No evidence for Haemophilus influenzae serotype replacement in Europe after introduction of the Hib conjugate vaccine. Lancet Infect Dis 2008;8:275-6. http://dx.doi.org/10.1016/ S1473-3099(08)70078-1. PMID:18471770

99. Cripps AW. Nontypeable Haemophilus influenzae and childhood pneumonia. P N G Med J 2010;53:147-50. PMID:23163185

100. Shann F, Gratten M, Germer S, Linnemann V, Hazlett D, Payne R. Aetiology of pneumonia in children in Goroka Hospital, Papua New Guinea. Lancet 1984;2:537-41. http://dx.doi. org/10.1016/S0140-6736(84)90764-5. PMID:6147602

101. Gratten M, Montgomery J. The bacteriology of acute pneumonia and meningitis in children in Papua New Guinea: assumptions, facts and technical strategies. P N G Med J 1991;34:185-98. PMID:1750263

102. Wall RA, Corrah PT, Mabey DC, Greenwood BM. The etiology of lobar pneumonia in the Gambia. Bull World Health Organ 1986;64:553-8. PMID:3490924
103. Ghafoor A, Nomani NK, Ishaq Z, Zaidi SZ, Anwar F, Burney MI et al. Diagnoses of acute lower respiratory tract infections in children in Rawalpindi and Islamabad, Pakistan. Rev Infect Dis 1990;12 Suppl 8:S907-14. http://dx.doi.org/10.1093/ clinids/12.Supplement_8.S907. PMID:2270413

104. Weinberg GA, Ghafoor A, Ishaq Z, Nomani NK, Kabeer M, Anwar $\mathrm{F}$ et al. Clonal analysis of Hemophilus influenzae isolated from children from Pakistan with lower respiratory tract infections. J Infect Dis 1989;160:634-43. http://dx.doi. org/10.1093/infdis/160.4.634. PMID:2677160

105. Howie SR, Morris GA, Tokarz R, Ebruke BE, Machuka EM, Ideh RC et al. Etiology of severe childhood pneumonia in The Gambia, West Africa, determined by conventional and molecular microbiological analyses of lung and pleural aspirate samples. Clin Infect Dis 2014;59:682-5. http:// dx.doi.org/10.1093/cid/ciu384. PMID:24867789

106. Yin CC, Huah LW, Lin JT, Goh A, Ling H, Moh CO. Lower respiratory tract infection in hospitalized children. Respirology 2003;8:83-9. http://dx.doi.org/10.1046/ j.1440-1843.2003.00430.x. PMID:12856747

107. Rahman M, Hossain S, Baqui AH, Shoma S, Rashid H, Nahar $\mathrm{N}$ et al. Haemophilus influenzae type- $\mathrm{b}$ and nonb-type invasive diseases in urban children (<5years) of Bangladesh: implications for therapy and vaccination. J Infect 2008;56:191-6. http://dx.doi.org/10.1016/j. jinf.2007.12.008. PMID:18280571

108. Gentile A, Bardach A, Ciapponi A, Garcia-Marti S, Aruj $P$, Glujovsky $D$ et al. Epidemiology of communityacquired pneumonia in children of Latin America and the Caribbean: a systematic review and meta-analysis. Int J Infect Dis 2012;16:e5-15. http://dx.doi.org/10.1016/j. ijid.2011.09.013. PMID:22056731

109. Levine OS, O'Brien KL, Deloria-Knoll M, Murdoch DR, Feikin DR, DeLuca AN et al. The Pneumonia Etiology Research for Child Health Project: a 21st century childhood pneumonia etiology study. Clin Infect Dis 2012;54 Suppl 2:S93-101. http://dx.doi.org/10.1093/cid/cir1052. PMID:22403238

110. Claesson BA, Lagergård T, Trollfors B. Antibody response to outer membrane of noncapsulated Haemophilus influenzae isolated from the nasopharynx of children with pneumonia. Pediatr Infect Dis J 1991;10:104-8. http://dx.doi. org/10.1097/00006454-199102000-00005. PMID:2062599

111. Claesson BA, Lagergård T, Trollfors B. Serum antibody responses to nonencapsulated Haemophilus influenzae isolated from the nasopharynx of children with pneumonia. J Infect Dis 1992;165 Suppl 1:S205-6. http:// dx.doi.org/10.1093/infdis/165-Supplement_1-S205. PMID:1588168

112. Korppi M, Katila ML, Jääskeläinen J, Leinonen M. Role of non-capsulated Haemophilus influenzae as a respiratory pathogen in children. Acta Paediatr 1992;81:989-92. http://dx.doi.org/10.1111/j.1651-2227.1992.tb12160.x. PMID:1290864

113. Korppi M, Heiskanen-Kosma T, Jalonen E, Saikku P, Leinonen $\mathrm{M}$, Halonen $\mathrm{P}$ et al. Aetiology of community-acquired pneumonia in children treated in hospital. Eur J Pediatr 1993;152:24-30. http://dx.doi.org/10.1007/BF02072512. PMID:8444202

114. Heiskanen-Kosma T, Korppi M, Jokinen C, Kurki S, Heiskanen $\mathrm{L}$, Juvonen $\mathrm{H}$ et al. Etiology of childhood pneumonia: 
serologic results of a prospective, population-based study. Pediatr Infect Dis J 1998;17:986-91. http://dx.doi. org/10.1097/00006454-199811000-00004. PMID:9849979

115. Murphy TF. Respiratory infections caused by non-typeable Haemophilus influenzae. Curr Opin Infect Dis 2003;16:12934. http://dx.doi.org/10.1097/00001432-20030400000009. PMID:12734445

116. Everett ED, Rham AE Jr, Adaniya R, Stevens DL, McNitt TR. Haemophilus influenzae pneumonia in adults. JAMA 1977;238:319-21. http://dx.doi.org/10.1001/ jama.1977.03280040039016. PMID:301574

117. Gotfried MH. Epidemiology of clinically diagnosed community-acquired pneumonia in the primary care setting: results from the 1999-2000 respiratory surveillance program. Am J Med 2001;111 Suppl 9A:25S9S. http://dx.doi.org/10.1016/S0002-9343(01)01028-2. PMID:11755440

118. Barnes DJ, Naraqi S, Igo JD. Haemophilus influenzae pneumonia in Melanesian adults: report of 15 cases. Thorax 1987;42:889-91. http://dx.doi.org/10.1136/thx.42.11.889. PMID:3321545

119. Barnes DJ, Naraqi S, Igo JD. The role of percutaneous lung aspiration in the bacteriological diagnosis of pneumonia in adults. Aust N Z J Med 1988;18:754-7. http://dx.doi. org/10.1111/j.1445-5994.1988.tb00174.x. PMID:3266552

120. Janssens JP, Krause KH. Pneumonia in the very old. Lancet Infect Dis 2004;4:112-24. http://dx.doi.org/10.1016/ S1473-3099(04)00931-4. PMID:14871636

121. El-Solh AA, Sikka P, Ramadan F, Davies J. Etiology of severe pneumonia in the very elderly. Am J Respir Crit Care Med 2001;163:645-51. http://dx.doi.org/10.1164/ ajrccm.163.3.2005075. PMID:11254518

122. Patel IS, Seemungal TA, Wilks M, Lloyd-Owen SJ, Donaldson GC, Wedzicha JA. Relationship between bacterial colonisation and the frequency, character, and severity of COPD exacerbations. Thorax 2002;57:759-64. http:// dx.doi.org/10.1136/thorax.57.9.759. PMID:12200518

123. Campos J, Hernando M, Román F, Pérez-Vázquez M, Aracil B, Oteo J et al.; Group of Invasive Haemophilus Infections of the Autonomous Community of Madrid, Spain. Analysis of invasive Haemophilus influenzae infections after extensive vaccination against $\mathrm{H}$. influenzae type $\mathrm{b}$. J Clin Microbiol 2004;42:524-9. http://dx.doi.org/10.1128/JCM.42.2.524529.2004. PMID:14766811

124. Berndsen MR, Erlendsdóttir H, Gottfredsson M. Evolving epidemiology of invasive Haemophilus infections in the post-vaccination era: results from a long-term populationbased study. Clin Microbiol Infect 2012;18:918-23. http://dx.doi.org/10.1111/j.1469-0691.2011.03700.x. PMID:22070637
125. Torres A, Blasi F, Peetermans WE, Viegi G, Welte T. The aetiology and antibiotic management of communityacquired pneumonia in adults in Europe: a literature review. Eur J Clin Microbiol Infect Dis 2014;33:1065-79. http:// dx.doi.org/10.1007/s10096-014-2067-1. PMID:24532008

126. Peto L, Nadjm B, Horby P, Ngan TT, van Doorn R, Van Kinh N et al. The bacterial aetiology of adult community-acquired pneumonia in Asia: a systematic review. Trans R Soc Trop Med Hyg 2014;108:326-37. http://dx.doi.org/10.1093/ trstmh/tru058. PMID:24781376

127. Ladhani SN, Collins S, Vickers A, Litt DJ, Crawford C, Ramsay $\mathrm{ME}$ et al. Invasive Haemophilus influenzae serotype e and $\mathrm{f}$ disease, England and Wales. Emerg Infect Dis 2012;18:72532.http://dx.doi.org/10.3201/eid1805.111738. PMID:22515912

128. Ladhani S, Slack MP, Heath PT, von Gottberg A, Chandra M, Ramsay ME; European Union Invasive Bacterial Infection Surveillance participants. Invasive Haemophilus influenzae Disease, Europe, 1996-2006. Emerg Infect Dis 2010;16:45563.http://dx.doi.org/10.3201/eid1603.090290. PMID:20202421

129. Resman F, Ristovski M, Ahl J, Forsgren A, Gilsdorf JR, Jasir A et al. Invasive disease caused by Haemophilus influenzae in Sweden 1997-2009; evidence of increasing incidence and clinical burden of non-type $b$ strains. Clin Microbiol Infect 2011;17:1638-45. http://dx.doi.org/10.1111/j.14690691.2010.03417.x. PMID:21054663

130. Ulanova M, Tsang RS. Haemophilus influenzae serotype a as a cause of serious invasive infections. Lancet Infect Dis 2014;14:70-82. http://dx.doi.org/10.1016/S14733099(13)70170-1. PMID:24268829

131. Bruce MG, Deeks SL, Zulz T, Navarro C, Palacios C, Case $C$ et al. Epidemiology of Haemophilus influenzae serotype a, North American Arctic, 2000-2005. Emerg Infect Dis 2008;14:48-55. http://dx.doi.org/10.3201/ eid1401.070822. PMID:18258076

132. Menzies RI, Markey P, Boyd R, Koehler AP, Mclntyre PB. No evidence of increasing Haemophilus influenzae non-b infection in Australian Aboriginal children. Int J Circumpolar Health 2013;72:20992. http://dx.doi.org/10.3402/ijch. v72i0.20992. PMID:23984279

133. Klein JO. Role of nontypeable Haemophilus influenzae in pediatric respiratory tract infections. Pediatr Infect Dis J 1997;16 Suppl:S5-8. http://dx.doi.org/10.1097/00006454199702001-00002. PMID:9041620

134. Chang $A B$, Ooi MH, Perera D, Grimwood K. Improving the diagnosis, management, and outcomes of children with pneumonia: Where are the gaps? Front Pediatr 2013;1:29. http://dx.doi.org/10.3389/fped.2013.00029. PMID:24400275 